TAO, Vol. 16, No. 1, 177-213, March 2005

\title{
A Modeling Study of Typhoon Toraji (2001): Physical Parameterization Sensitivity and Topographic Effect
}

\author{
Ming-Jen Yang ${ }^{1, *}$ and Lin Ching ${ }^{2}$
}

(Manuscript received 21 May 2004, in final form 8 December 2004)

\begin{abstract}
This paper investigates the dependence of simulated track, central pressure, maximum wind, and accumulated rainfall of Typhoon Toraji (2001) on physical parameterizations, using the fifth-generation Pennsylvania State University- National Center for Atmospheric Research Mesoscale Model (MM5). The model configuration includes three nested domains with grid size of 60,20 , and $6.67 \mathrm{~km}$, respectively. Three sets of five numerical experiments on cumulus, cloud microphysics, and planetary boundary layer (PBL) parameterizations are performed (15 experiments totally). Among subgrid-scale cumulus schemes tested, the simulated typhoon with the Grell scheme has the best track. For grid-scale cloud microphysics scheme examined, all storms have similar tracks, with the best simulated track using the Goddard Graupel cloud microphysics scheme. The PBL parameterization substantially affects the simulated typhoon tracks, and the storm with the Medium-Range Forecast model PBL has track and intensity that most resemble actual observations.

An experiment with the best scheme from each of three sets of physical parameterization experiments has the best performance in terms of central pressure, maximum wind and accumulated rainfall; it can simulate the westward turning of Toraji's track right before the landfall. Standard deviation and ensemble (arithmetic) mean are calculated for each set of physical parameterization experiments. The ensemble-mean track and rainfall distribution are much closer to the observations than each individual experiment. A combination of the topographically- and environmentallyinduced vertical moisture fluxes, calculated based on the flux model of Lin et al. (2001), corresponded well to the hourly surface rainfall distribution.
\end{abstract}

\footnotetext{
${ }^{1}$ Institute of Hydrological Sciences, National Central University, Chung-Li, Taiwan, ROC

2 Department of Atmospheric Sciences, Chinese Culture University, Taipei, Taiwan, ROC

* Corresponding author address.Dr. Ming-Jen Yang, Institute of Hydrological Sciences, National Central University, Chung-Li, Taiwan, ROC; E-mail: mingjen@cc.ncu.edu.tw
} 


\begin{abstract}
An analysis of nondimensional parameters for typhoon's track continuity over the Taiwan island shows that Typhoon Toraji's track discontinuity is consistent with the control parameter analysis proposed by Lin et al. (2002). The westward turning of Toraji's track right before the landfall may be caused by horizontal advection process due to flow blocking, on the basis on a momentum budget analysis.
\end{abstract}

(Key words: Typhoon, Physical parameterization, Topographic effect, Toraji, MM5)

\title{
1. INTRODUCTION
}

The importance of cumulus convection within tropical cyclones (TCs) has been recognized for a long time (Charney and Eliassen 1964; Kuo 1965), and one of the reasons for development of cumulus parameterization schemes (CPSs) is to represent the effects of subgridscale cumulus clouds in TC simulations by grid-scale prognostic variables (Ooyama 1969, 1982; Kuo 1974; Anthes 1977; Frank 1983). Although there are now several CPSs available to use in numerical models, a systematic comparison of CPSs in a TC simulation is still important for typhoon forecasting over the Taiwan area.

From a cloud-resolving model simulation of an intense squall line, Yang and Houze (1995) indicated that the simulated rainfall amount, distribution, and internal mesoscale structure were highly sensitive to the hydrometeor types and microphysical schemes implemented in the model. Liu et al. (1997) successfully simulated the track, storm intensity, and detailed inner-core structure of Hurricane Andrew (1992), using the fifth-generation Pennsylvania State University-National Center for Atmospheric Research Mesoscale Model (MM5) with a grid nesting down to a 6-km grid size and a sophisticated explicit-scale cloud microphysics scheme. Wang (2002) further indicated that the detailed cloud structures of an idealized TC were quite different with various cloud microphysics schemes, although the intensification rate and final intensity were not very sensitive to the details of microphysics parameterizations.

Braun and Tao (2000) used the Penn State/NCAR MM5 model to examine the sensitivity of TC simulation to available planetary boundary layer (PBL) parameterizations. Significant differences were found, with minimum central pressures varying by up to $16 \mathrm{hPa}$ and maximum winds by $15 \mathrm{~m} \mathrm{~s}^{-1}$, and simulated horizontal precipitation distribution and TC intensity varied substantially between different PBL schemes. In particular, the Burk and Thompson (1989) and bulk aerodynamic schemes produced the strongest TC, while the Medium-Range Forecast (MRF) model PBL scheme (Hong and Pan 1996) produced the weakest storm.

In this study, we will first investigate the sensitivity of simulated track, central pressure, maximum wind, and accumulated rainfall of Typhoon Toraji (2001) on physical parameterizations, using the Penn State/NCAR MM5 model. Then, we will discuss the topographic effects on Toraji, which include the generation of heavy orographic rainfall and the degree of deflection of the storm's track by Taiwan's topography. Toraji made landfall over Hualian County at 1610 UTC 29 July 2001 and left Taiwan from Hsinchu County at 0220 UTC 30 July (Fig. 1). During its passage over Taiwan, Toraji dumped abundant rainfall over 
mountain slopes and cascades, and caused severe landslides, debris flows, and flash flooding, which resulted in tremendous property damage and loss of human life.

For the orographic rainfall issue, we will follow the flux method of Lin et al. (2002) to see how much Toraji's precipitation over Taiwan is related to topography-enhanced moisture flux (Wu and Kuo 1999; Lin et al. 2001; Wu et al. 2002). For the track deflection issue, we will estimate flow and topographic parameters proposed by Lin et al. $(2002 ; 2005)$ and investigate

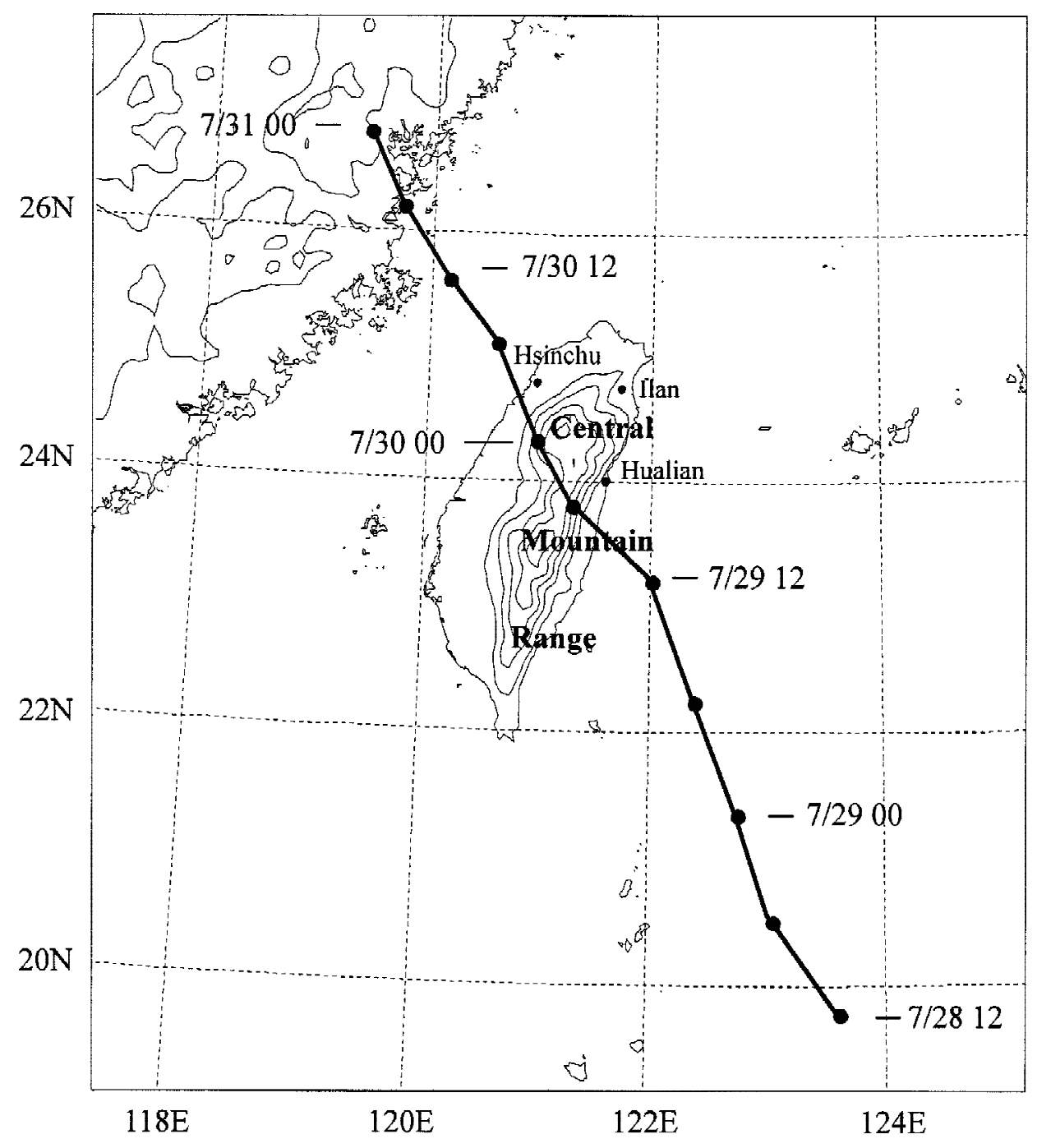

Fig. 1. The JTWC best track of Typhoon Toraji from 1200 UTC 28 July to 0000 UTC 31 July 2001. A dot along the track represents the typhoon's pressure center every 6 hours. The contour interval for terrain height is $500 \mathrm{~m}$. 
whether or not these control parameters for Typhoon Toraji's case are in agreement with those in previous studies (Bender et al. 1987; Yeh and Elsberry 1993a, b; Lin et al. 1999). A momentum budget is conducted to understand the physical mechanisms responsible for the track turning right before Toraji's landfall on Taiwan.

\section{OBSERVATION ANALYSIS}

Typhoon Toraji (2001) basically followed a very straight track as it approached Taiwan, as shown in the best-track analysis of the Joint Typhoon Warning Center (JTWC) in Fig. 1. Toraji made landfall along the east coast of Taiwan near Showlin, Hualian County, around 1610 UTC 29 July 2001, and crashed directly into the Central Mountain Range (CMR). After crossing the CMR in 10 hours, it produced copious rainfall, severe debris flows and mudslides, and caused more than 100 deaths and about 300 people missing or injured, which made Toraji the most severe typhoon disaster over Taiwan in 2001 in terms of human casualties. Just before landfall, Toraji turned west and followed a slightly anticyclonic track across the island (Fig. 1). Such a track was quite different from cyclonic tracks in many previous observational and idealized modeling studies of TCs passing over Taiwan (Wang 1980; Chang 1982; Bender et al. 1987; Yeh and Elsberry 1993a, b; Lin et al. 1999).

Figure 2a shows the surface chart at 1200 UTC 28 July (hereafter 7/28/12UTC) 2001 from the global analysis of the European Center for Medium Range Weather Forecasts/Tropical Ocean Global Atmosphere (ECMWF/TOGA), which depicts synoptic environmental flows around Typhoon Toraji over eastern Asia and northwestern Pacific Ocean. The North Pacific subtropical high, located to the east of Toraji, and a high-pressure ridge north of Taiwan tended to steer Toraji northwestward toward Taiwan. A low-level jet (LLJ) can be seen on the 700hPa chart (Fig. 2b), which was associated with Toraji's outer circulation. This LLJ played an important role in the production of heavy topographic rainfall over the eastern slopes of the CMR (Fig. 3a), because it tended to induce strong upward vertical motion over the windward slopes in a conditionally unstable flow (Lin et al. 2001; 2002). The 700-, 500-, and 300-hPa charts (Figs. 2b, c and d) show a subtropical high pressure system over the northwestern Pacific Ocean. There was generally an easterly-to-southeasterly wind component east of Taiwan throughout the entire troposphere at this time.

Figure 3a shows the 24-h accumulated rainfall recorded by the CWB rain gauge network on 29 July. During this time period when the moisture-rich outer circulation of Typhoon Toraji was impinging on Taiwan's east coast, most of the rainfall occurred on the eastern slopes of the CMR. There was another rainfall maximum in the southern part of the CMR. The 24-h accumulated rainfall on 30 July is shown in Fig. 3b, which displays a maximum rainfall of around $664 \mathrm{~mm}$ over the southern peak of the CMR.

\section{MODEL AND NUMERICAL EXPERIMENTS}

The Penn State/NCAR MM5 (Grell et al. 1994; version 3.5) is used as a common model framework to help investigate the sensitivity of simulated track, central pressure, maximum 

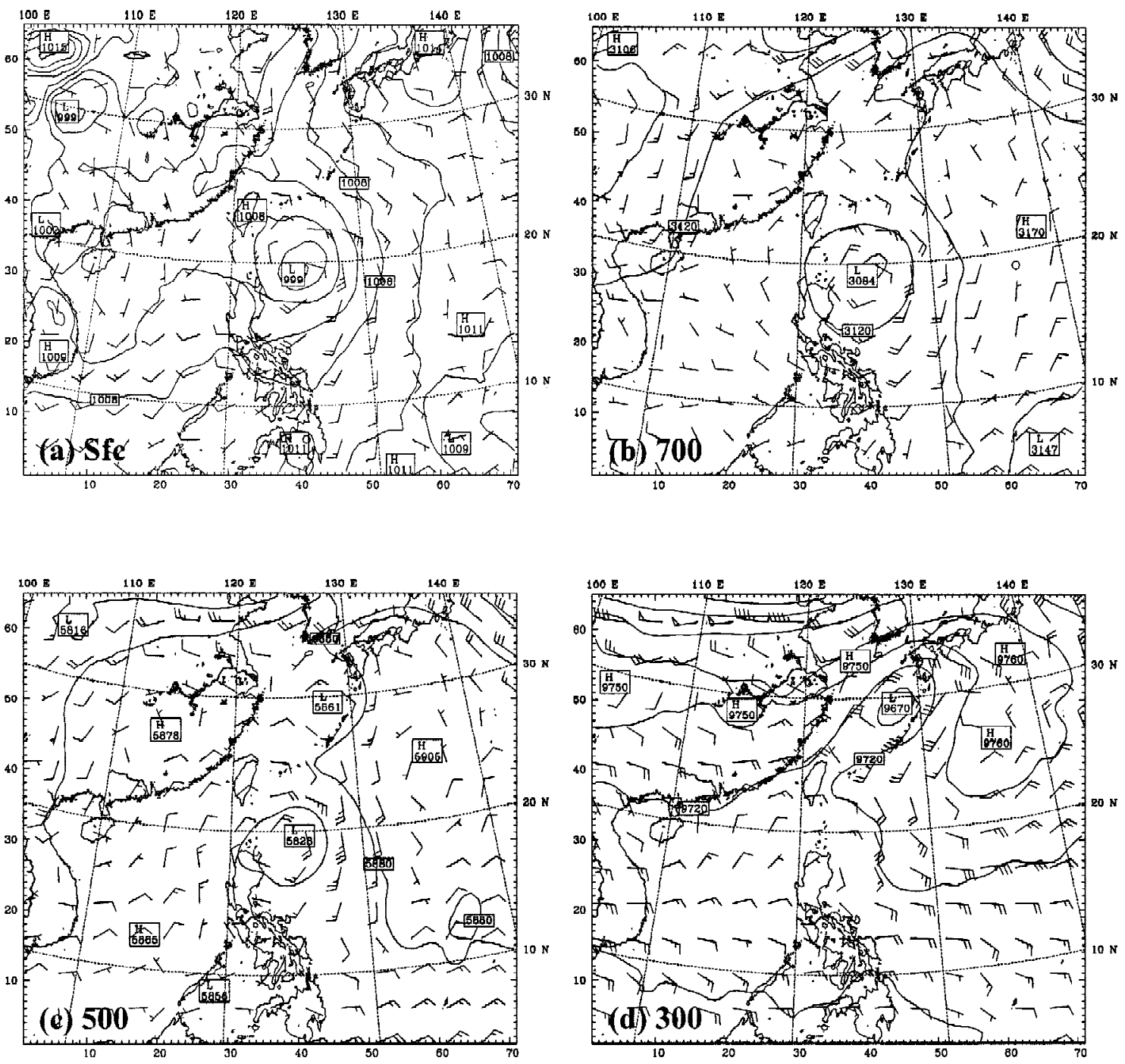

Fig. 2. The ECMWF analysis field at 1200 UTC 28 July 2001 for (a) surface, (b) 700, (c) 500, and (d) $300 \mathrm{hPa}$.

wind, and accumulated rainfall of Typhoon Toraji to physical parameterizations, as well as the topographic effects. Table 1 lists the combinations of physical parameterization schemes of all numerical experiments. The five CPSs compared in Set A are the Anthes-Kuo scheme (Kuo 1974; Anthes 1977), the Grell scheme (Grell 1993), the Kain-Fritsch scheme (Kain and Fritsch 1993), the Betts-Miller scheme (Betts and Miller 1986), and the updated Kain-Fritsch scheme (Kain 2004). The five cloud microphysics schemes chosen for evaluation in Set B are the Warm Rain scheme (Kessler 1969), the Simple Ice scheme (Dudhia 1989), the Mixed Phase scheme (Resinser et al. 1998), the Goddard Graupel scheme (Tao and Simpson 1993), and the 



Fig. 3. Twenty-four hour accumulated rainfall (in mm) on (a) 29 and (b) 30 July 2001 (LST). Rainfalls are contoured at 0, 20, 40, 70, and $90 \mathrm{~mm}$ in (a), and contoured at $0,100,200,300$, and $500 \mathrm{~mm}$ in (b). 
Schultz scheme (Schultz 1995). The five PBL schemes tested in Set C are the Blackadar scheme (Blackadar 1979), the Burk-Thompson scheme (Burk and Thompson 1989), the Eta MellorYamada scheme (Mellor and Yamada 1982), the Medium-Range Forecast model (MRF) PBL scheme (Hong and Pan 1996), and the Pleim-Xiu scheme (Xiu and Pleim 2000). In each set of experiments, all model setting and physics parameters remain the same, except for the testing physical parameterization scheme. Note that most of the physical schemes listed in Table 1 are the commonly used ones; this systematic comparison should be valuable, and sensitivity found in investigating Typhoon Toraji might be applicable to other typhoon cases with similar tracks and storm characteristics.

Table 1. Precipitation physics scheme used by each numerical experiment.

Experiment Cumulus scheme Microphysics scheme Boundary-layer scheme

Set A: Test of cumulus parameterization

$\begin{array}{llll}\text { AK } & \text { Anthes-Kuo } & \text { Goddard Graupel } & \text { MRF } \\ \text { GR* } & \text { Grell } & \text { Goddard Graupel } & \text { MRF } \\ \text { KF } & \text { Kain-Fritsch } & \text { Goddard Graupel } & \text { MRF } \\ \text { BM } & \text { Betts-Miller } & \text { Goddard Graupel } & \text { MRF } \\ \text { KF2 } & \text { new Kain-Fritsch } & \text { Goddard Graupel } & \text { MRF }\end{array}$

Set B: Test of microphysical parameterization

$\begin{array}{llll}\text { WR } & \text { Grell } & \text { Warm Rain } & \text { MRF } \\ \text { ICE } & \text { Grell } & \text { Simple Ice } & \text { MRF } \\ \text { MP } & \text { Grell } & \text { Mixed Phase } & \text { MRF } \\ \text { GG* } & \text { Grell } & \text { Goddard Graupel } & \text { MRF } \\ \text { SCH } & \text { Grell } & \text { Schultz } & \text { MRF }\end{array}$

Set C: Test of PBL parameterization

$\begin{array}{llll}\text { BD } & \text { Grell } & \text { Goddard Graupel } & \text { Blackadar } \\ \text { BT } & \text { Grell } & \text { Goddard Graupel } & \text { Burk-Thompson } \\ \text { ETA } & \text { Grell } & \text { Goddard Graupel } & \text { Eta Mellor-Yamada } \\ \text { MRF* } & \text { Grell } & \text { Goddard Graupel } & \text { MRF } \\ \text { PX } & \text { Grell } & \text { Goddard Graupel } & \text { Pleim-Xiu }\end{array}$

*: These three experiments are identical. 
The MM5 configuration includes a coarse mesh of $60-\mathrm{km}$ grid size, an intermediate mesh of $20-\mathrm{km}$ gird size, and a fine mesh of $6.67-\mathrm{km}$ grid size (Fig. 4). There are $65 \times 71$ grid points on the $60-\mathrm{km}$ grid, $109 \times 109$ grid points on the $20-\mathrm{km}$ grid, and $199 \times 163$ grid points on the 6 . 67-km grid, respectively; $23 \sigma$-levels are used in the vertical on all three grids. Note that no cumulus scheme is used on the $6.67-\mathrm{km}$ grid; otherwise all physical schemes are active on all three domains. Each MM5 run is 60 hours, starting at 1200 UTC 28 July and ending at 0000 UTC 31 July 2001. The same initial and boundary conditions for each MM5 run are provided by the $1.125^{\circ} \times 1.125^{\circ} \mathrm{ECMWF} / \mathrm{TOGA}$ global analysis. Sea surface temperature is taken from weekly mean analysis by the National Centers for Environmental Prediction (NCEP).

Because the vortex contained in the ECMWF/TOGA large-scale analysis is too weak and too broad, a TC initialization procedure described by Low-Nam and Davis (2001) is used to improve the representation of Toraji's initial structure. First the erroneously large vortex in the



Fig. 4. Computational domains for the 60-, 20-, and 6.67-km grid sizes. 
large-scale analysis is removed. Then an axisymmetric Rankine vortex is inserted into the wind field at the initialization time, with the storm characteristics $\left(40 \mathrm{~m} \mathrm{~s}^{-1}\right.$ of maximum wind and $50 \mathrm{~km}$ of maximum wind radius) estimated from the JTWC best-track analysis. When constructing the three-dimensional bogus wind, the axisymmetric wind is vertically weighted. The vertical weighting function is specified to be unity from the surface through $850 \mathrm{hPa}, 0.95$ at $700 \mathrm{hPa}, 0.9$ at $500 \mathrm{hPa}, 0.7$ at $300 \mathrm{hPa}, 0.6$ at $200 \mathrm{hPa}$, and 0.1 at $100 \mathrm{hPa}$. Then the nonlinear balance equation is used to solve the corresponding geopotential height perturbation, and the hydrostatic equation is used to obtain the temperature perturbation. Moisture is assumed to be near saturated (with relative humidity at 95\%) within the typhoon vortex.

\section{SENSITIVITY TO PHYSICAL PARAMETERIZATIONS}

\subsection{Track Comparison}

Figure 5 shows the simulated tracks of all physical parameterization experiments on the $6.67-\mathrm{km}$ grid. Note that the $6.67-\mathrm{km}$ simulation result can still be affected by the cumulus parameterization used on the outer 60 - and $20-\mathrm{km}$ domains through lateral boundary forcing, although the subgrid-scale cumulus scheme is not explicitly used on the $6.67-\mathrm{km}$ grid (Warner and Hsu 2000). Before landfall, all simulated TCs from cumulus and microphysics experiments moved slower than the observed TC, and the simulated tracks were close to each other (Figs. 5a, b). After landfall, all simulated cumulus and microphysics TCs moved faster than the actual TC, and the simulated tracks started to substantially deviate from each other. For the PBL experiments, there are significant differences of simulated TC tracks as early as 18 hours before the landfall (Fig. 5c and Table 2c).

\subsection{Intensity Comparison}

Figure 6 shows the simulated minimum central pressure of all physical parameterization experiments on the $6.67-\mathrm{km}$ grid. It is evident that the central pressure was underestimated in all experiments (CPS, MPH, and PBL), which might be due to not perfectly-balanced initial state, not fine enough gird resolution, and imperfect representation of physical processes. All cumulus and microphysics experiments captured the pressure filling during the landfall period (1610 UTC 29 July to 0220 UTC 30 July). There were substantial differences in the simulated central pressure for the microphysics experiments (Fig. 6b). In particular, the Warm Rain experiment produced the strongest storm, and the Simple Ice experiment had the weakest intensity. The reason why the Warm Rain experiment produced the lowest central pressure is because all hydrometeors in the Warm Rain experiment were heavy raindrops (compared to additional light ice particles and snowflakes in other microphysics experiments), falling out quickly and concentrating around the eyewall region, hydrostatically producing the lowest central pressure as shown in Wang (2002). For PBL experiments, all simulated TCs had weaker intensities as time increased (Fig. 6c), as a result of large track errors and improper interactions between simulated storms and Taiwan's topography. 

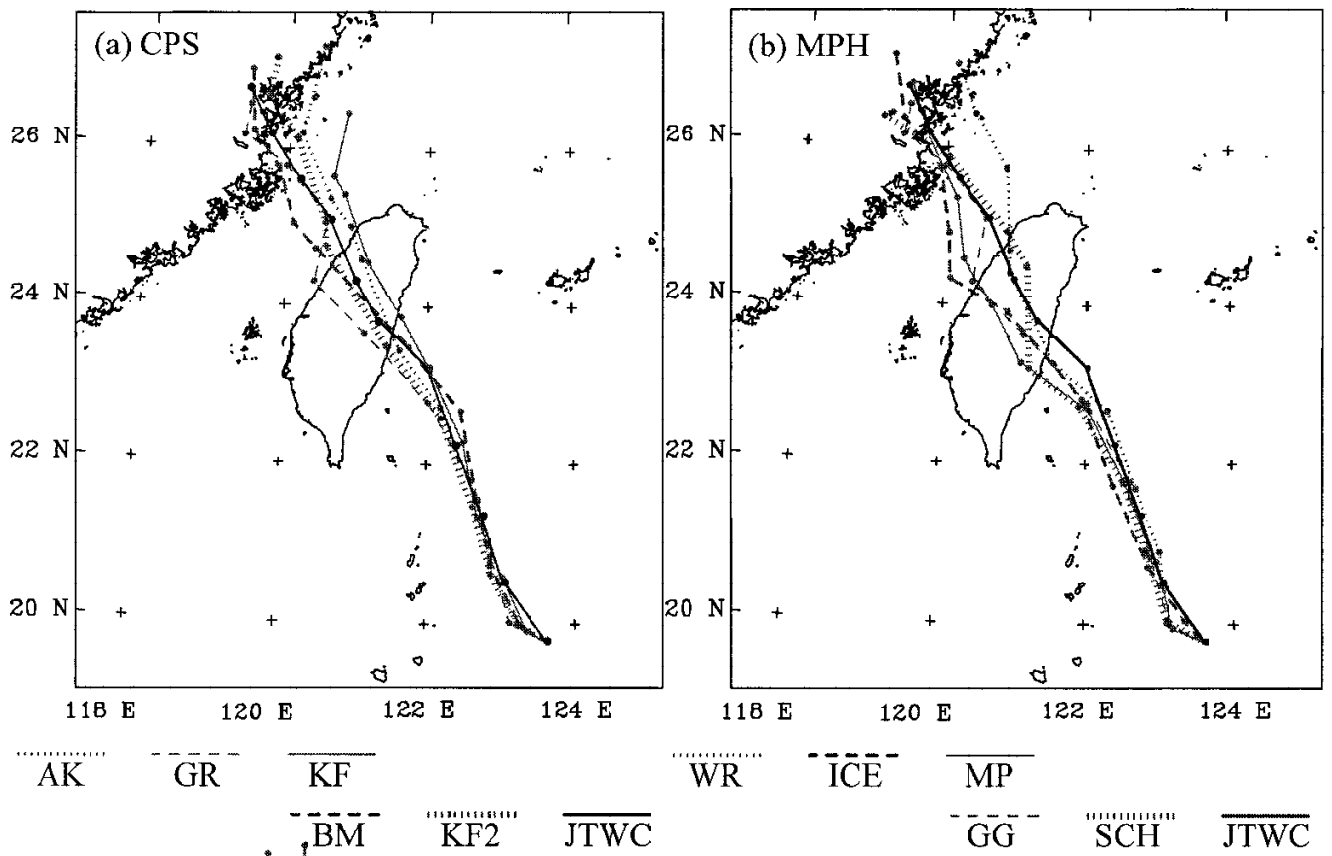

"W....... $\quad \overline{\mathrm{IC}} \overline{\mathrm{C}} \overline{-} \quad \overline{\mathrm{MP}}$

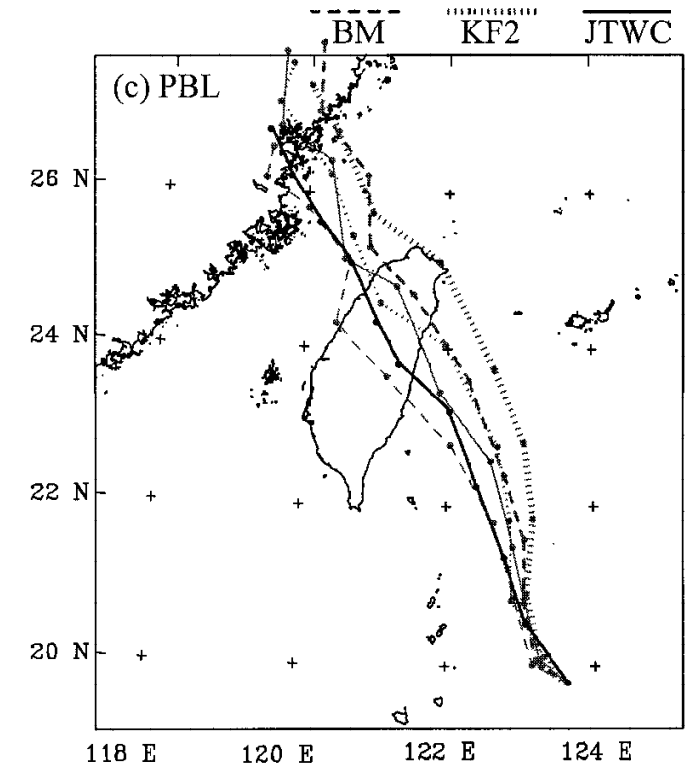

$\overline{\mathrm{GG}}-\quad$ SCH" $\overline{\mathrm{JTWC}}$

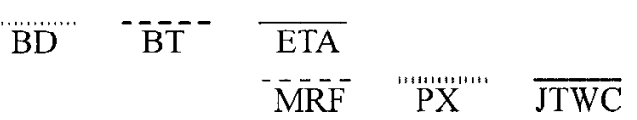

Fig. 5. The simulated tracks of the (a) cumulus (CPS), (b) microphysics (MPH), and (c) PBL parameteration experiments. The heavy solid line is the JTWC best track. A dot along the track represents the simulated typhoon's pressure center every 6 hours. 
Table 2a. Simulated track error (in $\mathrm{km}$ ) of the cumulus parameterization experiments.

\begin{tabular}{cccccccccccc}
\hline Time (hr) & 6 & 12 & 18 & 24 & 30 & 36 & 42 & 48 & 52 & 60 & Average \\
\hline AK & 60 & 63 & 79 & 57 & 52 & 35 & 32 & 46 & 37 & 115 & 58 \\
GR & 59 & 56 & 50 & 47 & 23 & 54 & 2 & 25 & 38 & 26 & 38 \\
KF & 71 & 83 & 99 & 113 & 98 & 80 & 82 & 64 & 106 & 136 & 93 \\
BM & 60 & 60 & 78 & 75 & 58 & 85 & 51 & 42 & 31 & 28 & 57 \\
KF2 & 62 & 74 & 85 & 69 & 39 & 71 & 8 & 59 & 61 & 51 & 58 \\
\hline
\end{tabular}

Table $2 \mathrm{~b}$. As in Table 2a but for the microphysics parameterization experiments.

\begin{tabular}{cccccccccccc}
\hline \hline Time (hr) & 6 & 12 & 18 & 24 & 30 & 36 & 42 & 48 & 52 & 60 & Average \\
\hline WR & 56 & 49 & 62 & 65 & 64 & 15 & 54 & 72 & 72 & 76 & 59 \\
ICE & 58 & 65 & 52 & 48 & 42 & 91 & 53 & 32 & 41 & 44 & 53 \\
MP & 63 & 61 & 50 & 57 & 60 & 41 & 64 & 25 & 3 & 8 & 43 \\
GG & 59 & 56 & 50 & 47 & 23 & 54 & 2 & 25 & 38 & 26 & 38 \\
SCH & 52 & 45 & 47 & 52 & 68 & 33 & 22 & 36 & 68 & 44 & 47 \\
\hline
\end{tabular}

Table 2c. As in Table 2a but for the PBL parameterization experiments.

\begin{tabular}{cccccccccccc}
\hline \hline Time (hr) & 6 & 12 & 18 & 24 & 30 & 36 & 42 & 48 & 52 & 60 & Average \\
\hline BD & 50 & 55 & 62 & 84 & 73 & 30 & 38 & 70 & 105 & 98 & 66 \\
BT & 53 & 66 & 95 & 123 & 103 & 66 & 36 & 93 & 68 & 139 & 84 \\
ETA & 52 & 60 & 92 & 92 & 72 & 63 & 8 & 89 & 72 & 112 & 71 \\
MRF & 59 & 56 & 50 & 47 & 23 & 54 & 2 & 25 & 38 & 26 & 38 \\
PX & 61 & 53 & 84 & 114 & 135 & 128 & 75 & 77 & 69 & 83 & 88 \\
\hline
\end{tabular}



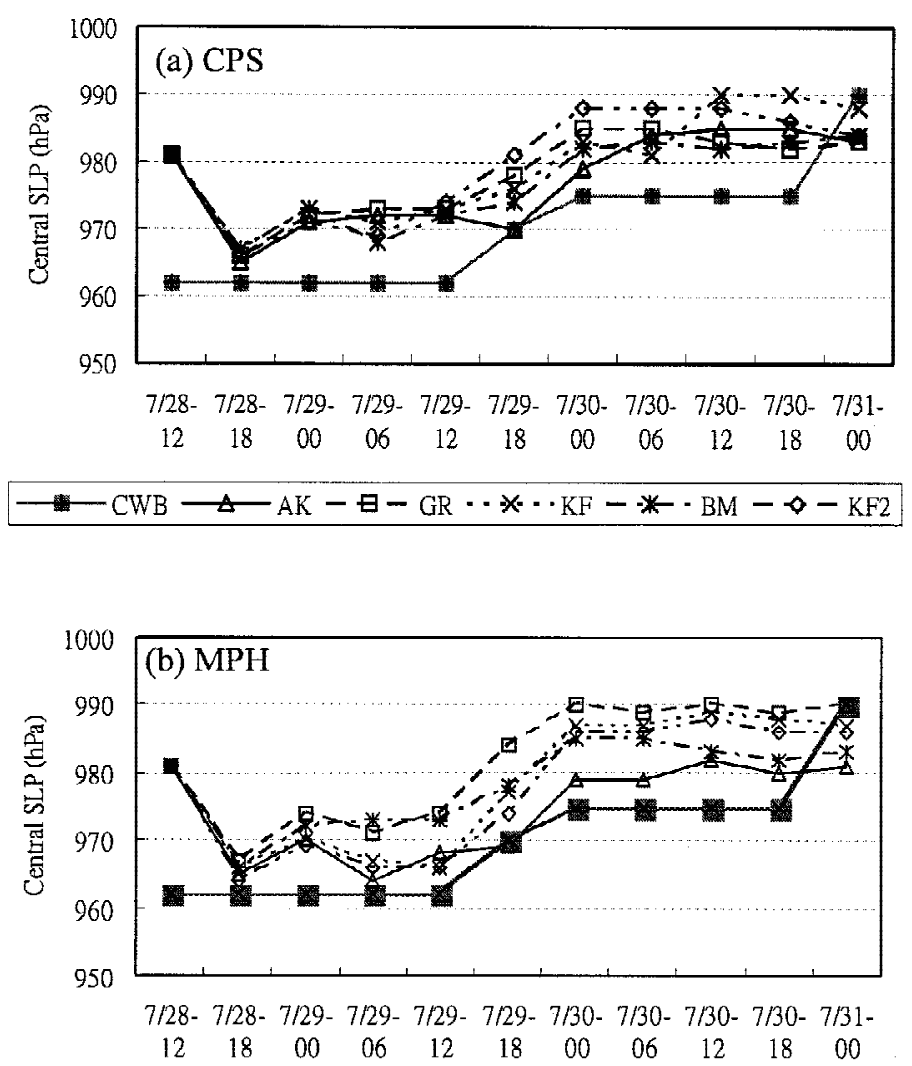

$-\mathrm{CWB}-\triangle \mathrm{WR}-\tau--\mathrm{ICE} \cdots \times \cdots \mathrm{MP}-\cdot * \cdot-\mathrm{GG}-\cdot \sigma \cdot \mathrm{SCH}$

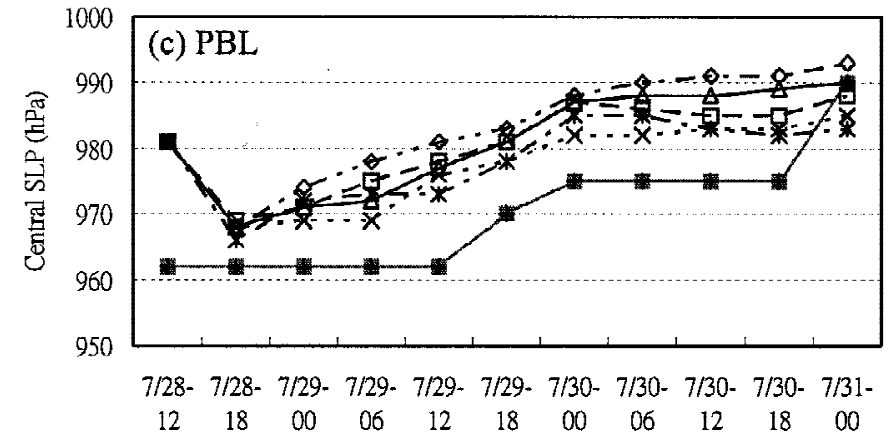

$\rightarrow-\mathrm{CWB} \rightarrow \mathrm{BD}-\mathrm{B}-\mathrm{BT}-* \cdots \mathrm{ETA}-*-\mathrm{MRF}-\diamond-\mathrm{PX}$

Fig. 6. As in Fig. 5 but for the time series of simulated minimum central pressure (in $\mathrm{hPa}$ ). 
Simulated maximum near-surface ( $0.995 \sigma$-level or roughly $40 \mathrm{~m}$ above surface) winds of all physics experiments on the $6.67-\mathrm{km}$ grid are shown in Fig. 7. Before landfall, all physical parameterization experiments (CPS, MPH, and PBL) had wind maximum close to the observed intensity, because all simulated TCs were initialized with the same Rankine vortex of the observed wind maximum. After hitting the CMR, all cumulus TCs quickly lost their strength and became much weaker than the observed (Fig. 7a). For microphysics experiments, all simulated TCs became weaker after landfall, except for the Warm Rain experiment whose wind maximum was close to or slightly stronger than the observed TC (Fig. 7b). Figure 7c shows great variability in the simulated TC's maximum wind to the PBL parameterizations implemented in the model.

\subsection{Precipitation Comparison}

Simulated 24-h accumulated rainfall distributions on 30 July 2001 by five cumulus experiments on the 6.67-km grid are shown in Fig. 8, and its corresponding observation is shown in Fig. 3b. It is clear from Fig. 8 that all cumulus experiments indicated precipitation maxima over the central and southern peaks of the CMR, with significant differences on the maximum rainfall amounts. To be specific, the maximum rainfalls ranged from $908 \mathrm{~mm}$ for the AnthesKuo experiment (AK) to $271 \mathrm{~mm}$ for the new Kain-Fritsch experiment (KF2), a difference of a factor of 3. The rainfall maxima of $\mathrm{AK}$ and $\mathrm{KF}$ experiments were more than the observed amount of $664 \mathrm{~mm}$ (also analyzed on the 6.67-km grid; see Fig. 3b). All microphysics experiments displayed very similar distribution of simulated 24-h rainfall (Fig. 9), and the difference in maximum rainfall amount was also smaller. In particular, the maximum rainfalls deviated from $566 \mathrm{~mm}$ for the Schultz experiment (SCH) to $265 \mathrm{~mm}$ for the Simple Ice experiment (ICE), a difference of a factor of 2. For the PBL experiments, owing to the larger deviations in simulated tracks, the resulting precipitation distributions were quite different (Fig. 10). For example, there was only one rainfall maximum for the Pleim-Xiu experiment (PX) over northern Taiwan, as a result of the most northward cyclonic turning of its simulated TC track (Fig. $5 c)$.

Based on the comparisons of simulated typhoon track, central pressure, maximum nearsurface wind, and 24-h accumulated rainfalls, the combination of best physics schemes in each physical parameterization experiment still produces the best simulation results. To be specific, the best-physics experiment (the MRF experiment; see Table 1) uses the Grell cumulus scheme, the Goddard Graupel cloud microphysics scheme, and the MRF PBL scheme. Discussion of topographic influences on the simulated TC in section 6 is thus based on the best-physics experiment result.

\section{ENSEMBLE ANALYSIS}

In order to reduce the sensitivity and uncertainty of the physical parameterizations, arithmetic average and standard deviation are calculated for each set of physics parameterization experiments. Figure 11 shows the ensemble average track (the heavy dashed "mean" line), the average-plus-one-standard-deviation track (the "mean+sd" line), and the average-minus-one- 

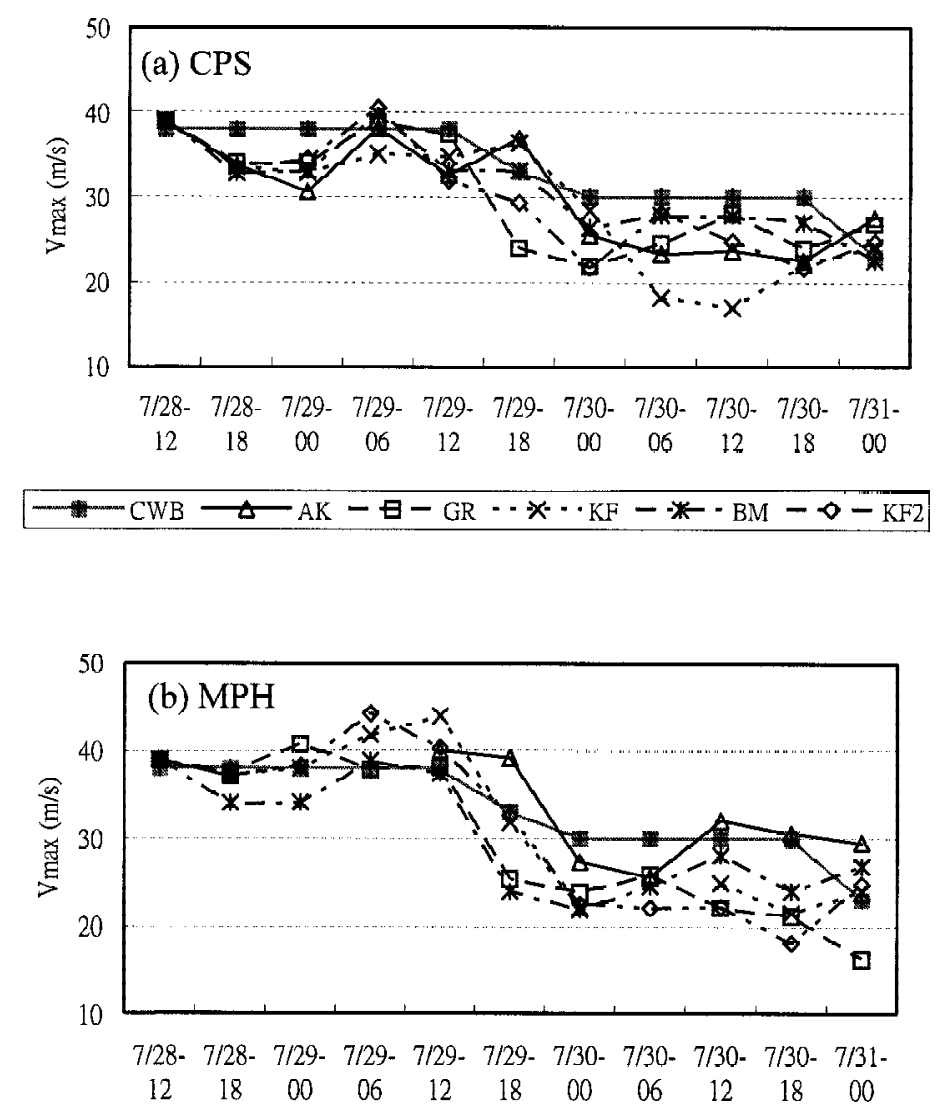

$-\mathrm{CWB}-\triangle-\mathrm{WR}-\boxminus-\mathrm{ICE} \cdots *-\cdot \mathrm{MP}-*-\mathrm{GG}-\infty-\mathrm{SCH}$

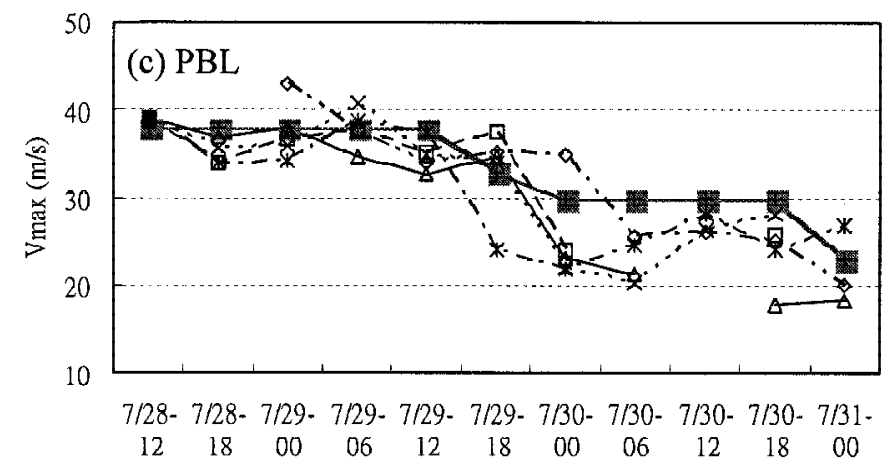

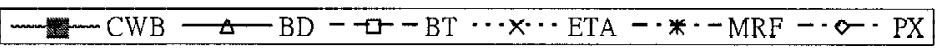

Fig. 7. As in Fig. 5 but for the time series of simulated maximum near-surface wind (in $\mathrm{m} \mathrm{s}^{-1}$ ). 


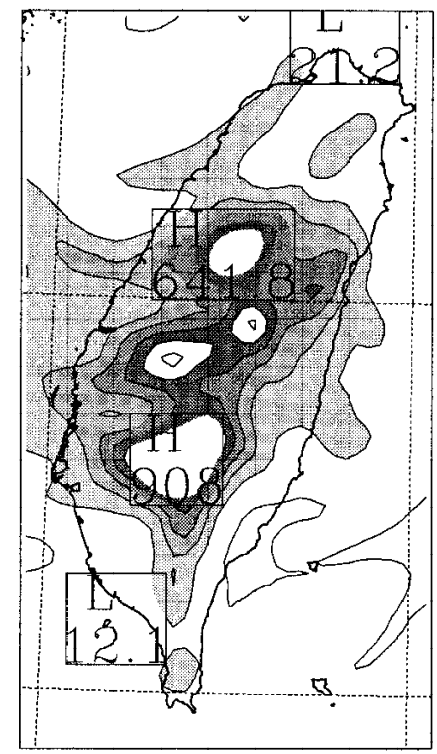

AK

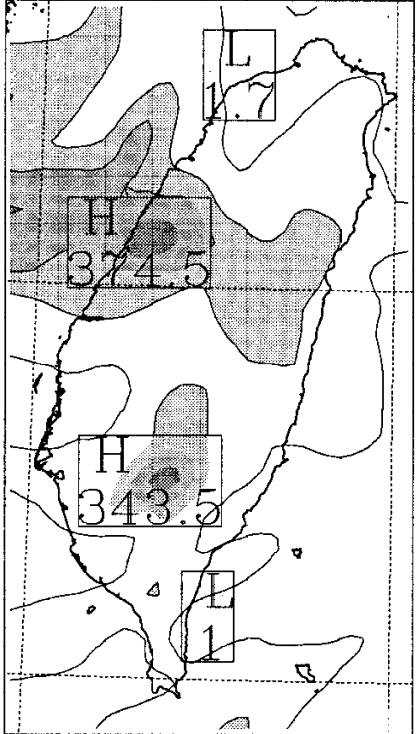

$\mathrm{BM}$

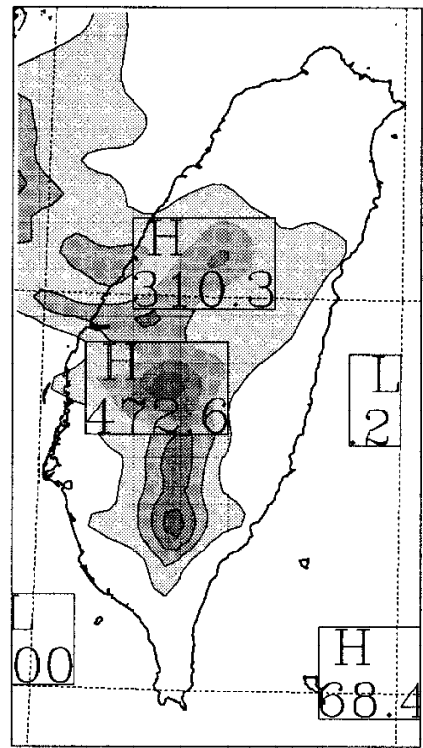

GR

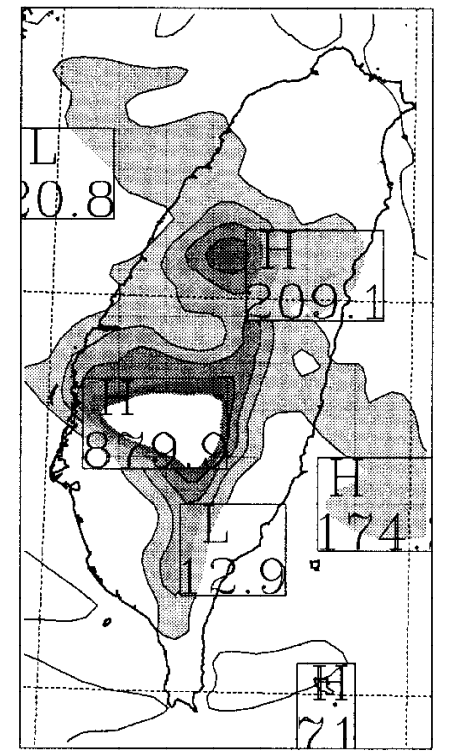

$\mathrm{KF}$
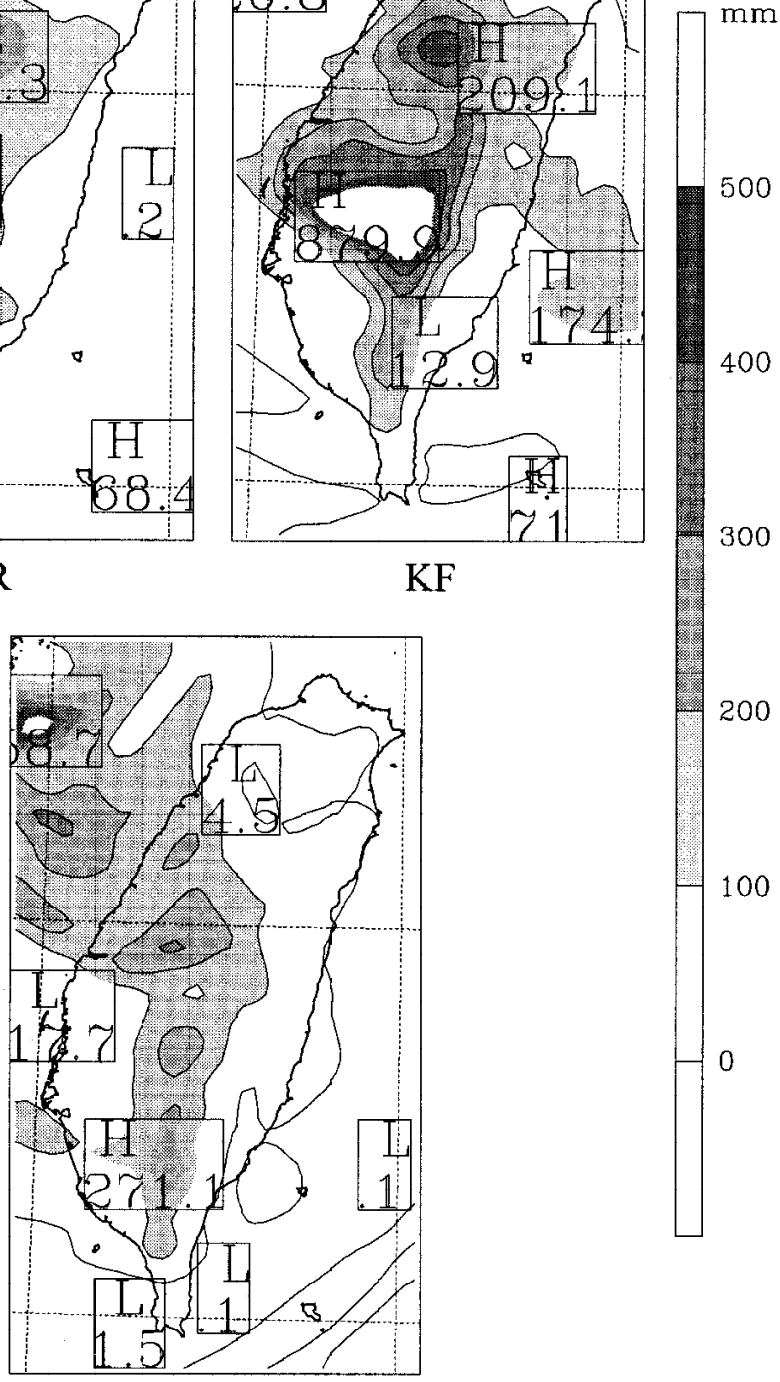

$\mathrm{KF} 2$

Fig. 8. Horizontal distribution of simulated 24-h accumulated rainfall (in $\mathrm{mm}$ ) on 30 July 2001 for five cumulus parameterization experiments on the $6.67-\mathrm{km}$ grid. 


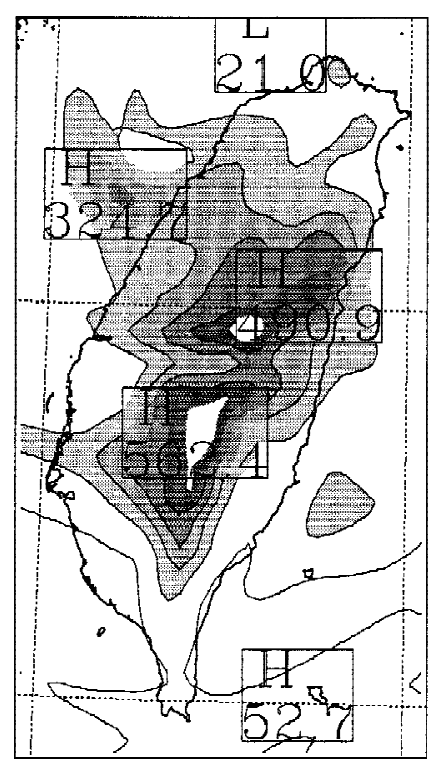

WR

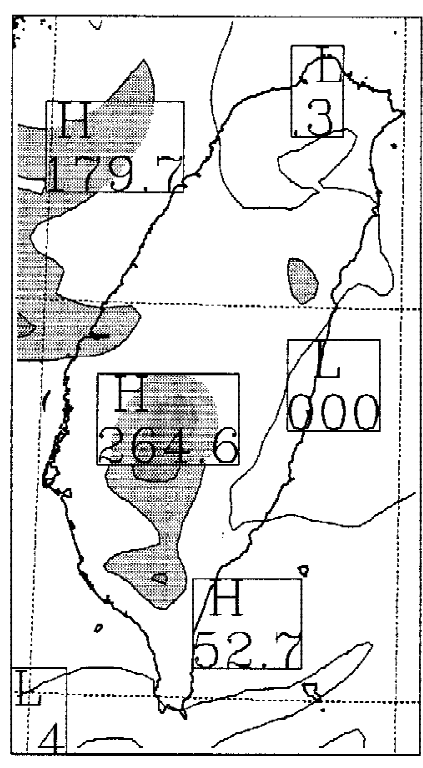

ICE
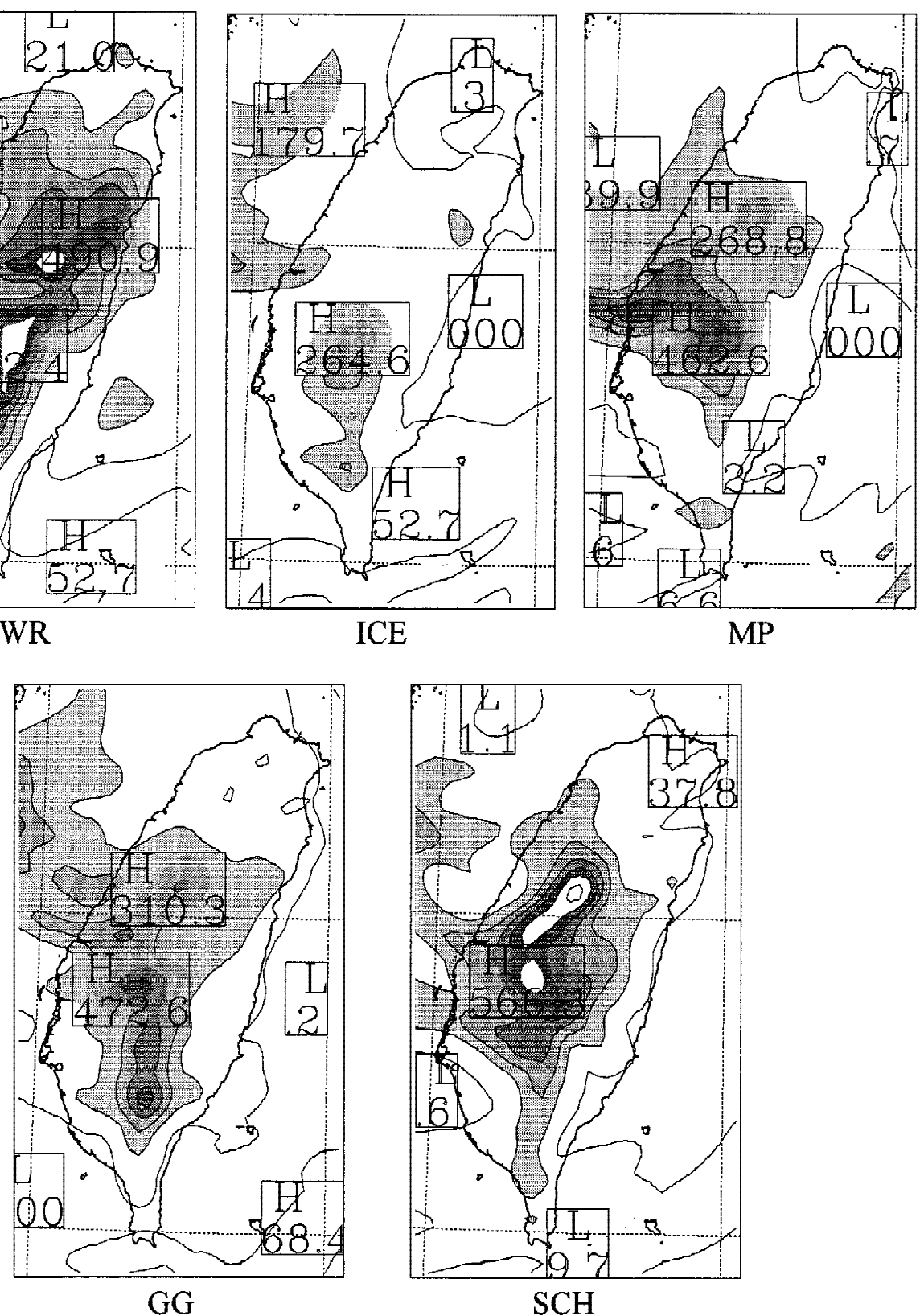

300

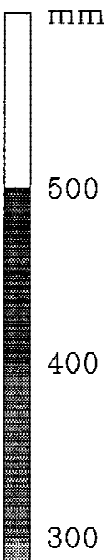

200

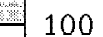

Fig. 9. As in Fig. 8 but for five microphysics parameterization experiments. 




$\mathrm{BD}$

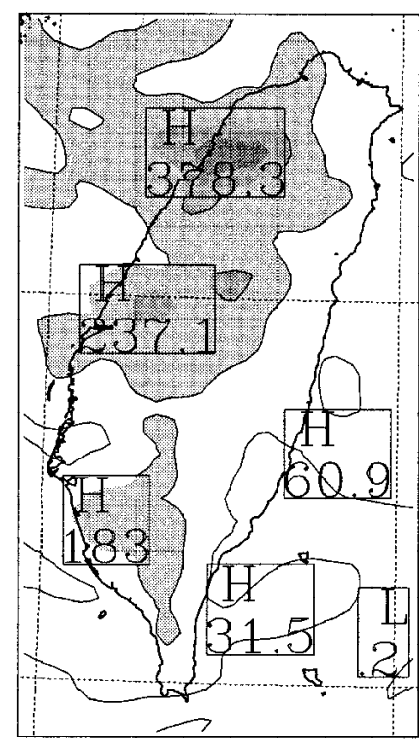

BT

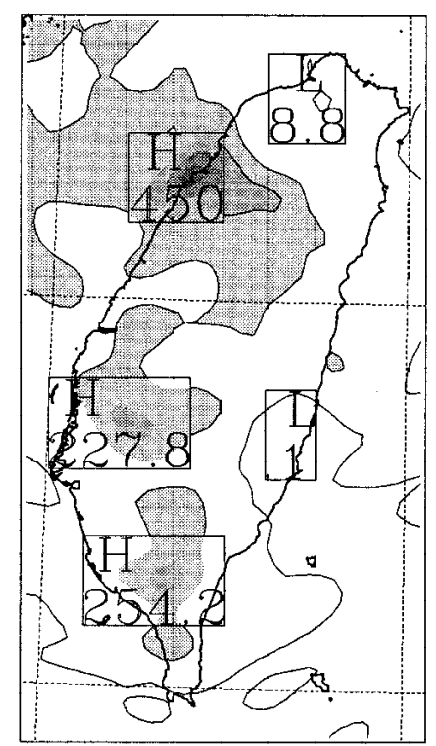

ETA

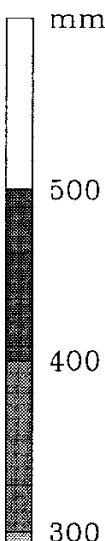

200


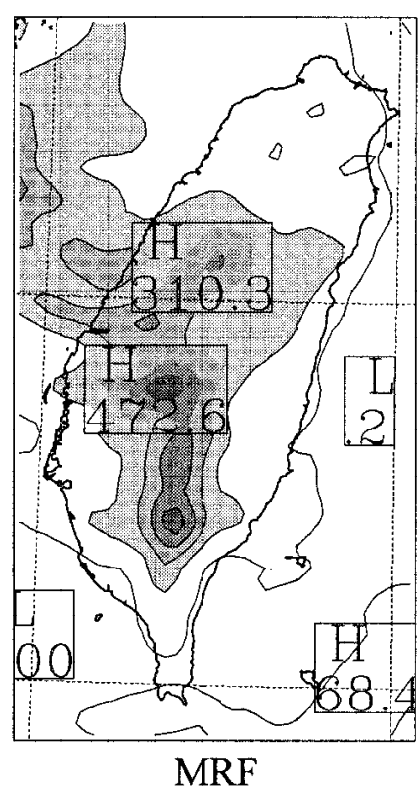

Fig. 10. As in Fig. 8 but for five PBL parameterization experiments. 
standard-deviation track (the "mean-sd" line) for all physical parameterization experiments. It is clear that the observed track (the solid line) is within the one-standard-deviation track envelop, and the ensemble mean track follows closely the observed track (especially for the CPS mean track), compared to any individual track in each physics experiments (see Fig. 5). Although each member in the PBL experiments has quite different track (Fig. 5c), the ensemble-mean track still strongly resembles the observed track (Fig. 11c).

The ensemble analysis of the minimum central pressure is shown in Fig. 12. Because all experiments underestimate storm intensity, the ensemble mean central pressure is still higher than the analyzed central pressure, and subtracting one standard deviation is not enough to make up the difference. Since all experiments are initialized with the same Rankine-vortex TC with the observed wind strength, the ensemble mean of simulated maximum wind is in good agreement with the observed wind maximum before TC's landfall (Fig. 13). After hitting Taiwan's terrain, all simulated TCs lose wind strength much faster than the actual TC; this is true for the ensemble mean wind speed in all cases even when one standard deviation is added.

The ensemble mean plus one standard deviation of 24-h accumulated rainfall on 30 July for the three sets of physical parameterizations is shown in Fig. 14. With one standard deviation considering the variations by different physical parameterizations, the resultant rainfall distribution is in better agreement with the observations (Fig. 3b), as indicated by Yang et al. (2004).

\section{TOPOGRAPHIC EFFECTS}

\subsection{Flux Model of Orographic Rainfall}

Lin et al. (2001) proposed that the orographic precipitation can be approximated by this formula:

$$
P=\frac{\rho}{\rho_{w}} E\left[\mathbf{V}_{\mathbf{H}} \cdot \nabla h+w_{e n v}\right] q \frac{L_{s}}{c_{s}},
$$

where $P$ is the total precipitation (in $\mathrm{m}$ ), $\rho$ the air density, $\rho_{w}$ the liquid water density, E the precipitation efficiency, $\mathbf{V}_{\mathbf{H}}$ the low-level horizontal flow velocity, $h$ the mountain height, $w_{e n v}$ the environmentally forced vertical motion, $q$ the water vapor mixing ratio, $L_{s}$ the horizontal scale of the convective system, and $c_{s}$ the propagation speed of the convective system. Lin et al. (2002) further considered a flux model, which includes both the orographicallyinduced vertical moisture flux $\left(\mathbf{V}_{\mathbf{H}} \cdot \nabla h\right) q$ and the synoptically-induced vertical moisture flux $w_{e n v} q$ for the incoming airflow. Then the rainfall distribution could be approximated by this flux model using the horizontal velocity $\mathbf{V}_{\mathbf{H}}$ and moisture $q$ fields.

Figures $15 \mathrm{~b}$ and $\mathrm{c}$ show the 850 -hPa synoptically-induced vertical moisture flux $w_{\text {env }} q$ and orographically-induced vertical moisture flux $\left(\mathbf{V}_{\mathbf{H}} \cdot \nabla h\right) q$, respectively, from the best physics combination (MRF) experiment on the $6.67-\mathrm{km}$ grid at $7 / 29 / 12 \mathrm{UTC}$. It is evident that 

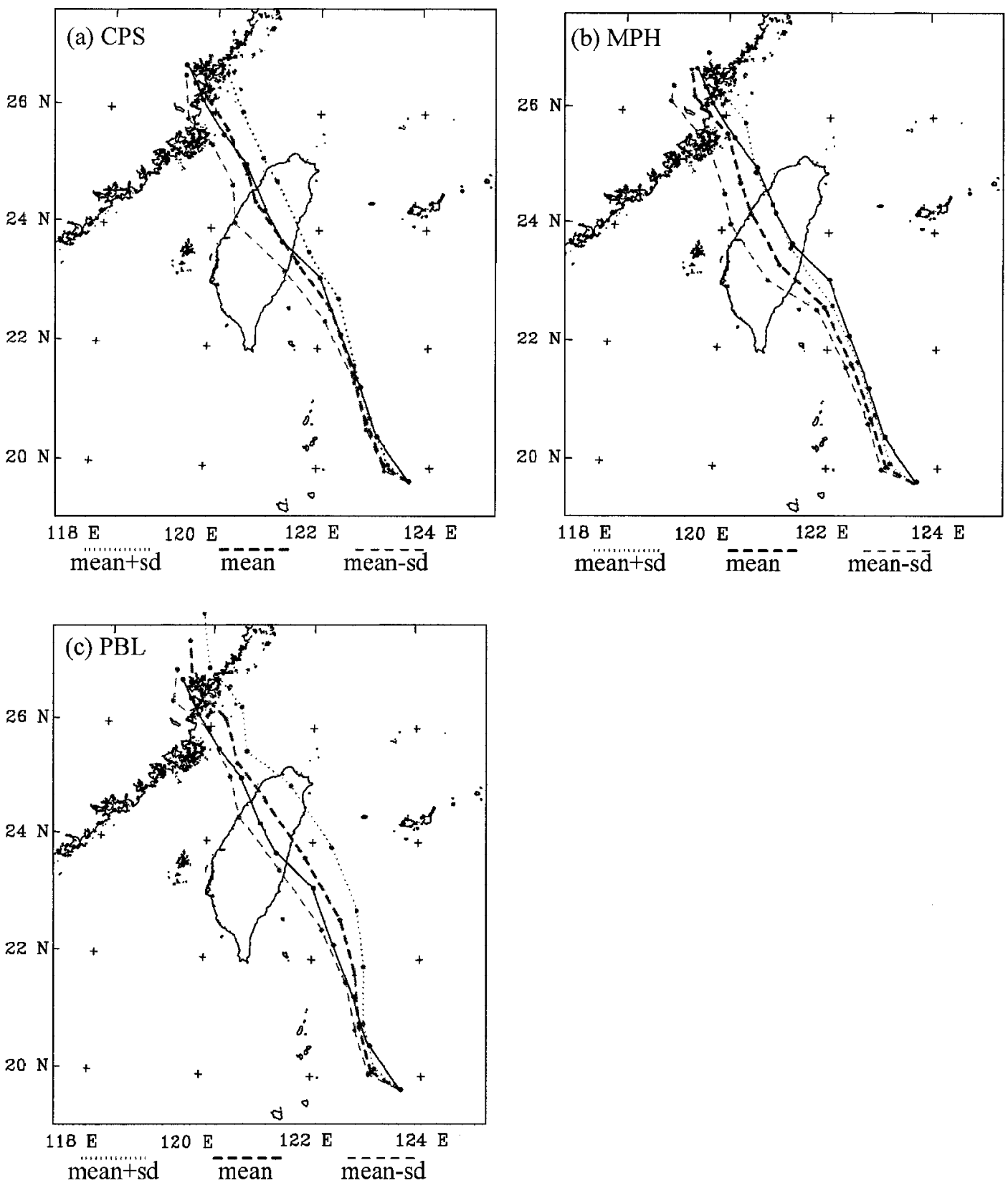

Fig. 11. Ensemble-analyzed tracks of the (a) cumulus (CPS), (b) microphysics $(\mathrm{MPH})$, and (c) PBL parameterization experiments. A dot along the track represents the typhoon's pressure center every 6 hours. Shown are the mean track, and the mean track plus and minus one standard deviation of distance variation. 

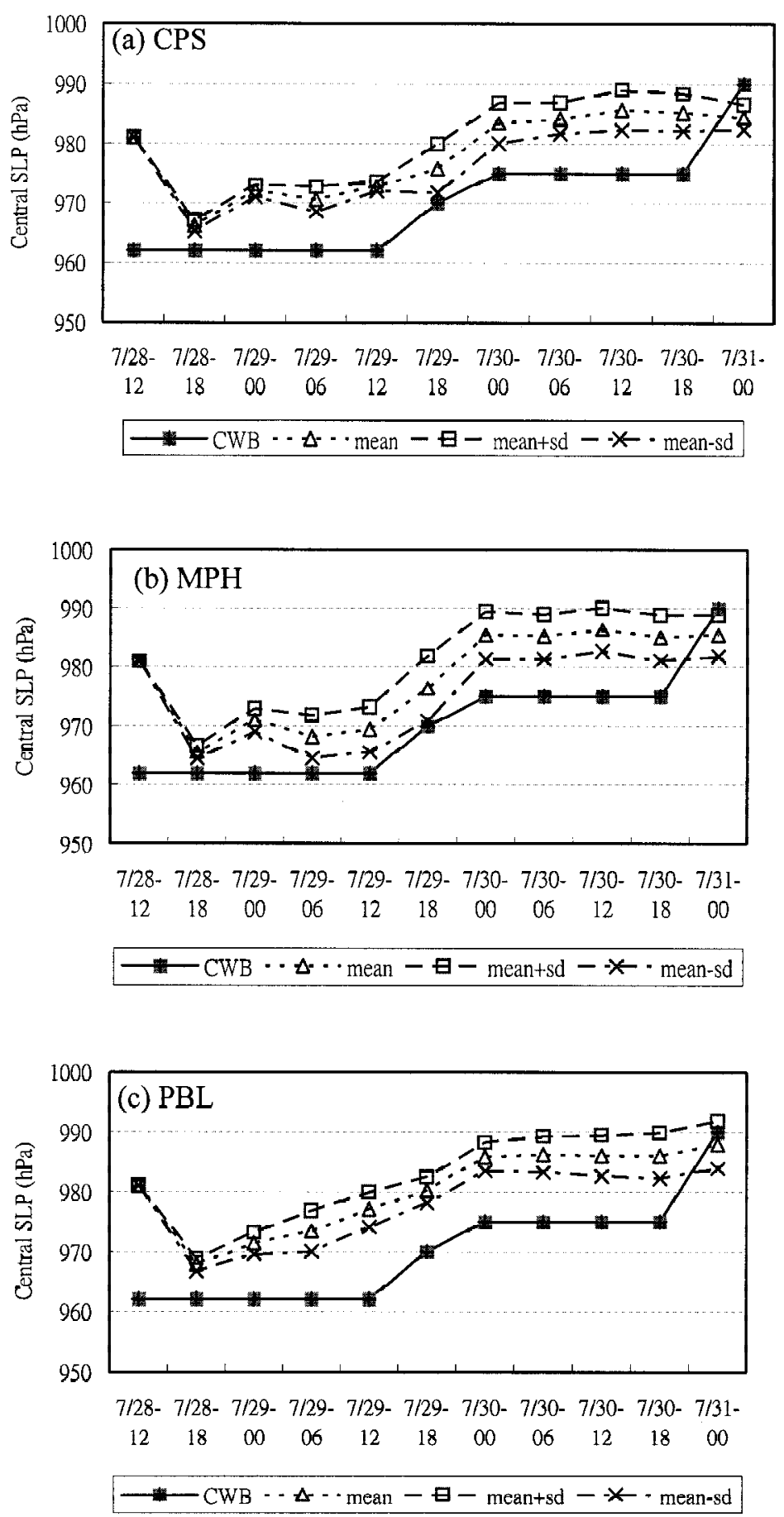

Fig. 12. As in Fig. 11 but for the simulated typhoon central pressure (in $\mathrm{hPa}$ ). 

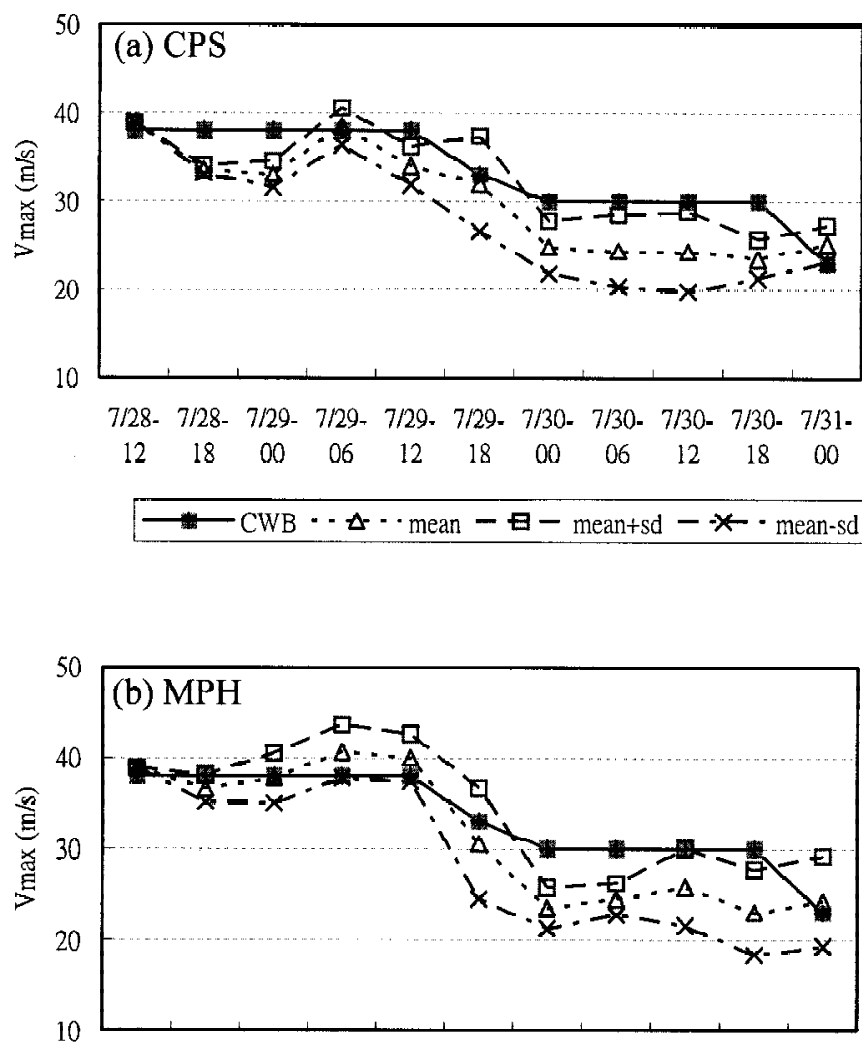

7/28- 7/28- 7/29- 7/29-7/29-7/29-7/30-7/30- 7/30-7/30-7/31-

$\begin{array}{lllllllllll}12 & 18 & 00 & 06 & 12 & 18 & 00 & 06 & 12 & 18 & 00\end{array}$

$\longrightarrow-$ CWB $\cdots \Delta-\cdot$ mean $-\boxminus-$ mean + sd $-\star \star-$ mean-sd

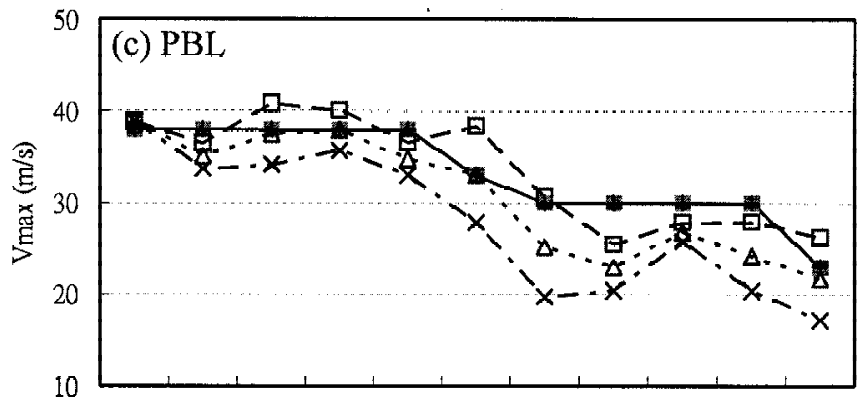

7/28- 7/28- 7/29- 7/29- 7/29- 7/29- 7/30- 7/30- 7/30- 7/30- 7/31-

$\begin{array}{lllllllllll}12 & 18 & 00 & 06 & 12 & 18 & 00 & 06 & 12 & 18 & 00\end{array}$

$\longrightarrow-$ CWB $\cdots \Delta \cdot \cdot$ mean $-\boxminus-$ mean + sd $-*-\cdot$ mean-sd

Fig. 13. As in Fig. 11 but for the simulated maximum near-surface wind (in $\mathrm{m} \mathrm{s}^{-1}$ ). 

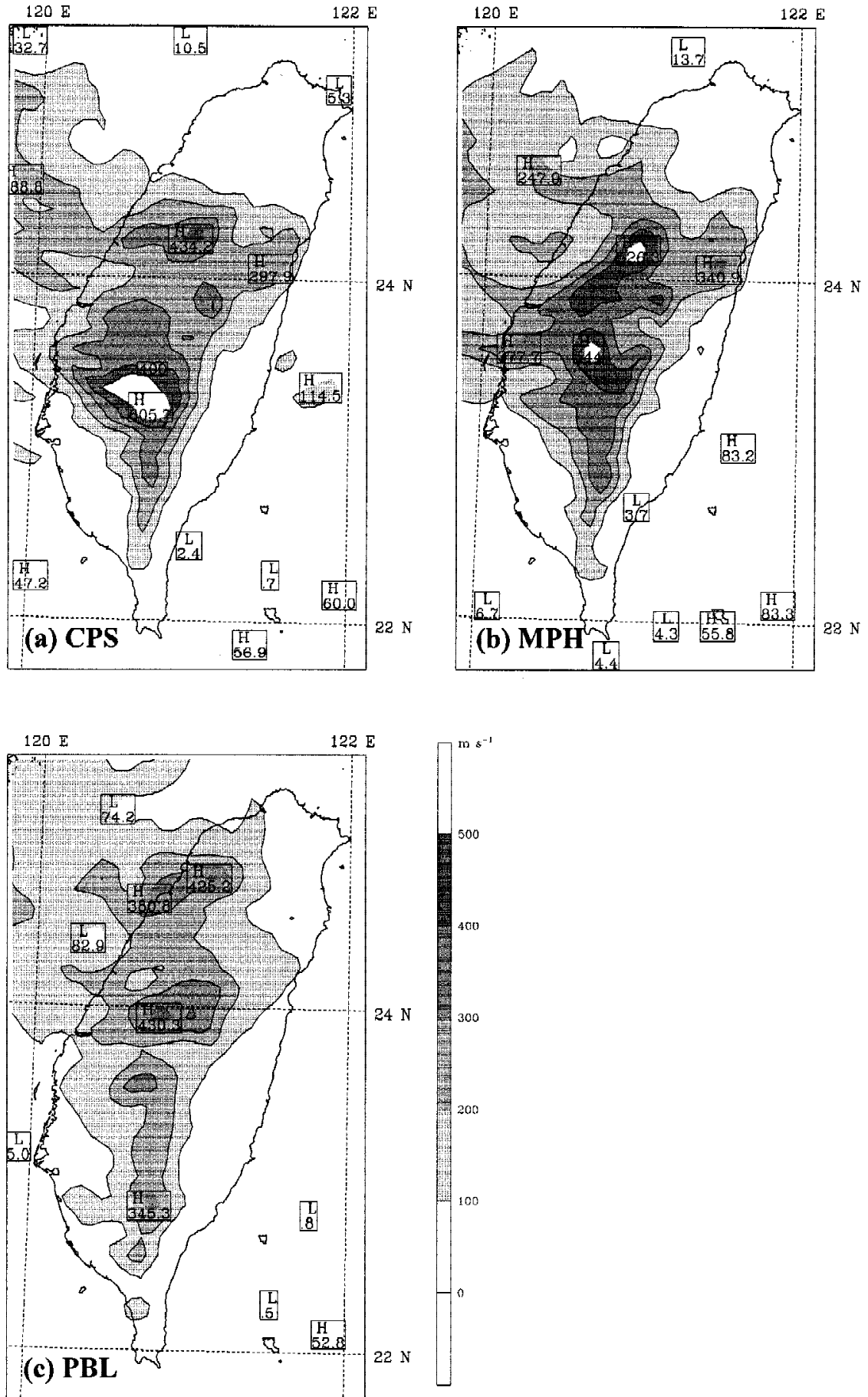

Fig. 14. As in Fig. 11 but for the simulated 24-h accumulated rainfall (in mm) on 30 July 2001 of the ensemble average plus one standard deviation. 
four hours before landfall (the observed TC was landing at 1610 UTC 29 July), both orographically-induced and synoptically-induced vertical moisture fluxes produced positive flux over the windward (eastern) side of the CMR, in good agreement with the pattern of hourly surface rainfall one hour later (Fig. 15a). Over the central or western (lee) side of the CMR, moisture fluxes generated by orographical forcing and typhoon vortex forcing were mostly negative. Twelve hours later (7/30/00UTC; Fig. 16) when the TC center was located near central Taiwan (Taichung area) over the west coast, the patterns of orographically-induced and synoptically-induced vertical moisture fluxes were reversed. To be specific, the orographic moisture flux over $850 \mathrm{hPa}$ was positive over the western (windward) side of the CMR (Fig. $16 c)$, corresponding very well to the horizontal distribution of intense hourly rainfall one hour later (Fig. 16a). The vertical moisture flux generated by the typhoon vortex forcing (Fig. 16b) was also mostly positive over the western coast and negative over the central CMR.

\subsection{Pressure and Circulation Centers}

Figure 17 shows the evolution of pressure fields and horizontal wind vectors of the bestphysics TC during the landfall period. At 7/29/12UTC, the simulated Toraji with vertically coherent low-pressure centers approached the southeast coast of Taiwan (left column of Fig. 17). At the surface, there was an inverted pressure ridge located over the eastern slope of the CMR duet, the CMR's blocking of the storm's outer circulation. A strong secondary low was also located over the northwestern coastal plain, which was produced by vorticity stretching and adiabatic warming associated with the strong downslope wind as part of the Toraji's circulation over the northern portion of the CMR (Chang 1982; Lin et al. 1999). At $700 \mathrm{hPa}$ (Fig. 17), the low pressure was collocated with the surface low, but no secondary low center produced on the lee (western) side of the mountain since most of the incoming flow was able to pass over the mountain at this level $(700 \mathrm{hPa})$. At both 500 and $300 \mathrm{hPa}$, the northern portion of the CMR was under the influence of an inverted trough and ridge. This inverted low- and highpressure perturbations indicated a hydrostatic wave response to Toraji's outer circulation (Smith 1979; Lin 1993).

The outer circulation of the simulated Toraji channeled through the mountains on both sides of the Taiwan Strait, resulted in a northeasterly gap flow (bottom row of Fig. 18). This northeasterly gap flow over the Taiwan Strait strengthened the formation of the secondary vortex along the lee (southwestern) side of the CMR, as shown in the surface relative vorticity field at 7/29/12UTC (Fig. 18). The overall airflow is less disturbed by the CMR at $300 \mathrm{hPa}$ (Figs. 17, 18), except for the hydrostatic mountain waves.

At 7/29/18UTC, the simulated TC made landfall over Hualian along the eastern coast of Taiwan. At the surface, a secondary low over northwestern Taiwan was as strong as or slightly weaker than the typhoon low over eastern Taiwan (the bottom row of Fig. 17). There were banners of positive and negative relative vorticity fields associated with mountain gaps and peaks at $700 \mathrm{hPa}$ (Fig. 18). Thus, the tracks of both the low-pressure and vorticity centers of the simulated Toraji were discontinuous, as a result of the coexistence of the typhoon and secondary (leeside) centers.

At 7/30/00UTC, the simulated Toraji was leaving Taiwan and entering the Taiwan Strait. 

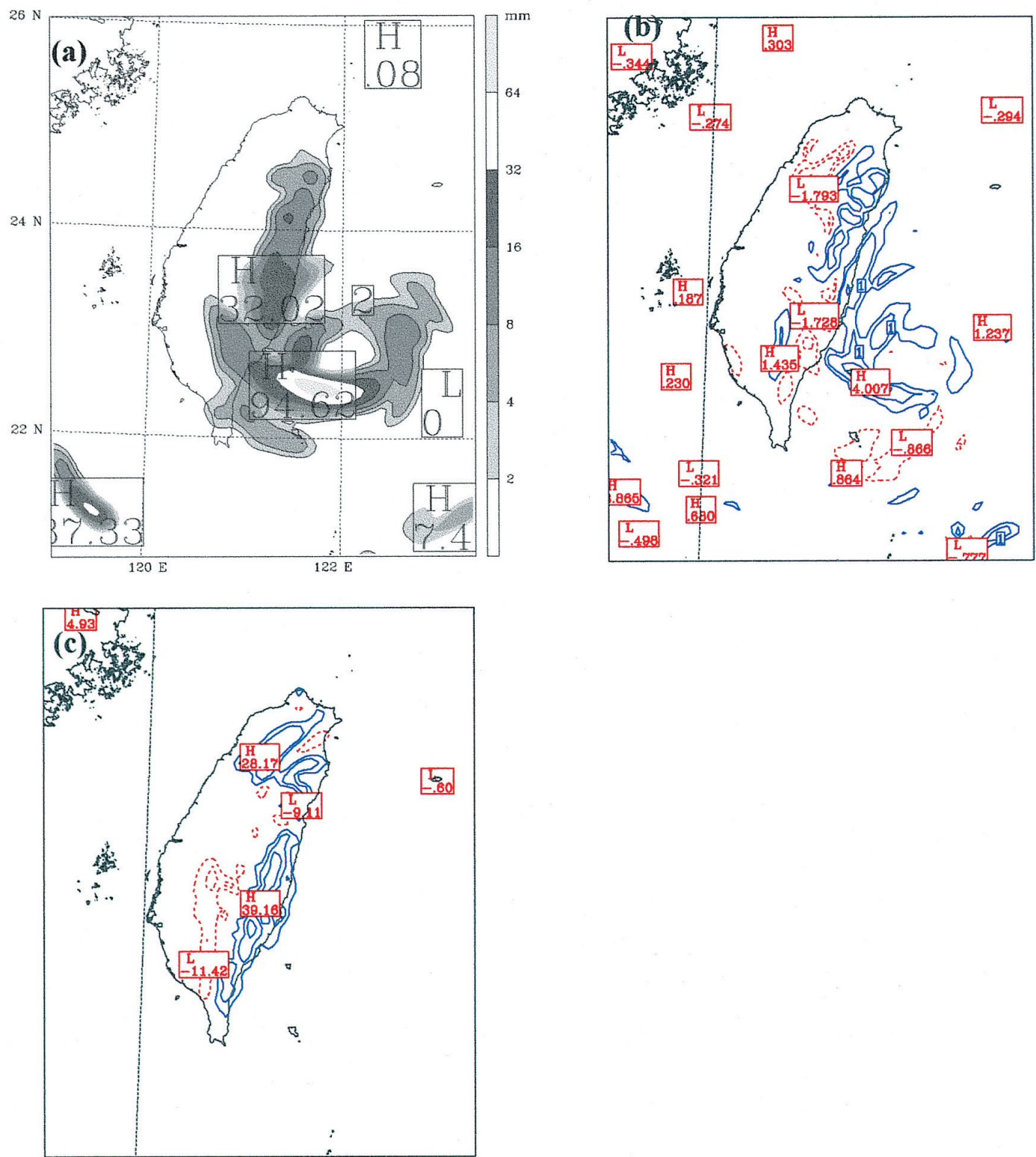

Fig. 15. (a) Simulated 1-h accumulated rainfall (in mm) valid at 1200-1300 UTC, (b) the synoptically-induced vertical moisture flux [wq; in units of $\left(\mathrm{m} \mathrm{s}^{-1}\right)$ $\left(\mathrm{g} \mathrm{kg}^{-1}\right)$ ] from the MRF experiment valid at 7/29/12UTC, and (c) the corresponding orographically-induced vertical moisture flux $\left(\mathbf{V}_{\mathbf{H}} \cdot \nabla h\right) q$. Contoured are at $\pm 0.5, \pm 1,2$, and $4\left(\mathrm{~m} \mathrm{~s}^{-1}\right)\left(\mathrm{g} \mathrm{kg}^{-1}\right)$ in $(\mathrm{b})$, and \pm 5 , \pm 10 , and $20\left(\mathrm{~m} \mathrm{~s}^{-1}\right)\left(\mathrm{g} \mathrm{kg}^{-1}\right)$ in (c). 

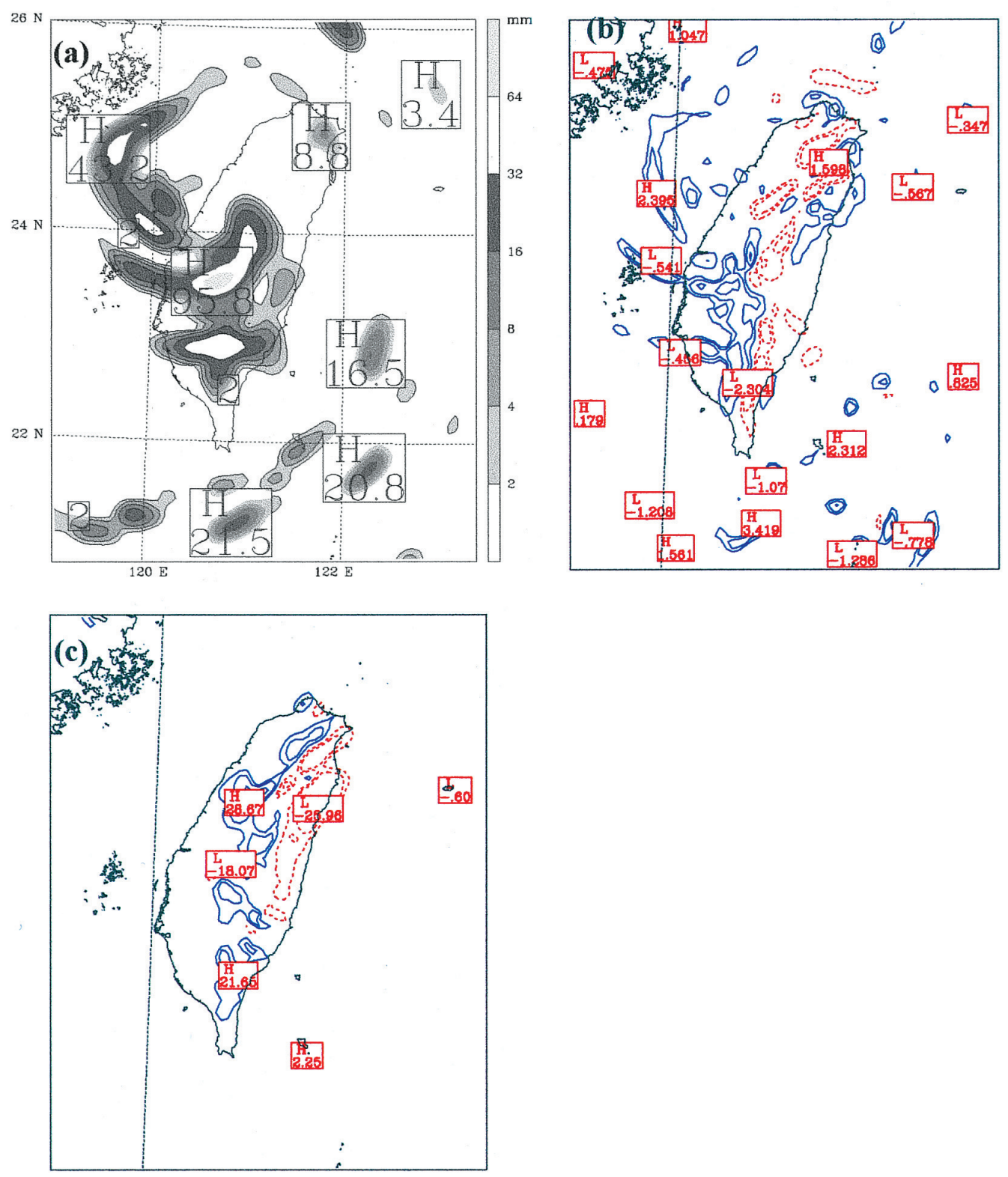

Fig. 16. As in Fig. 15 but for (a) 1-h rainfall (in mm) from 0000-0100 UTC 30 July, (b) synoptically-induced vertical moisture flux at 7/30/00UTC, and (c) the corresponding orographically-induced vertical moisture flux. 
7/29/12UTC

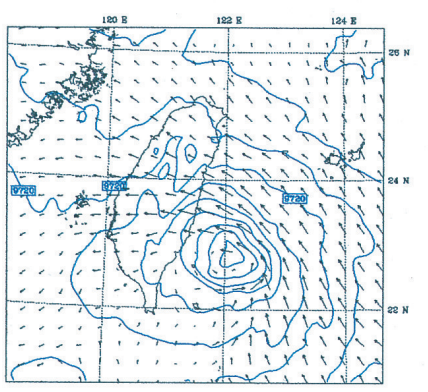

300

500

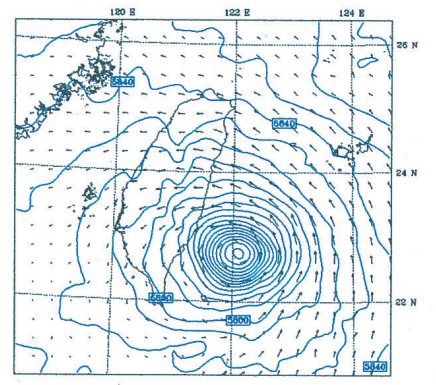

700
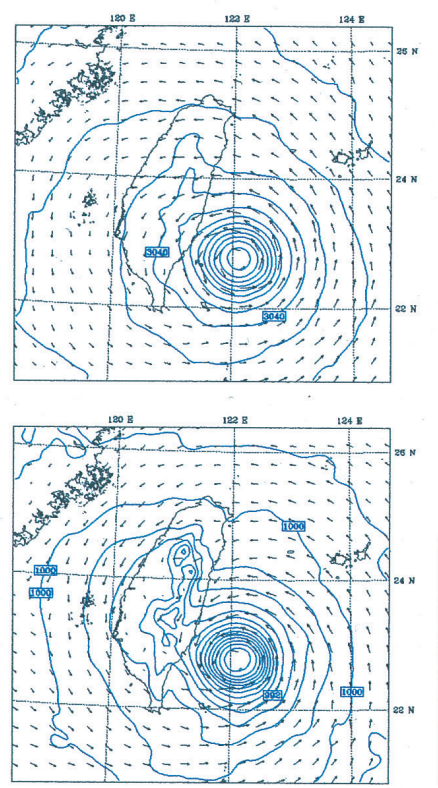

7/29/18UTC
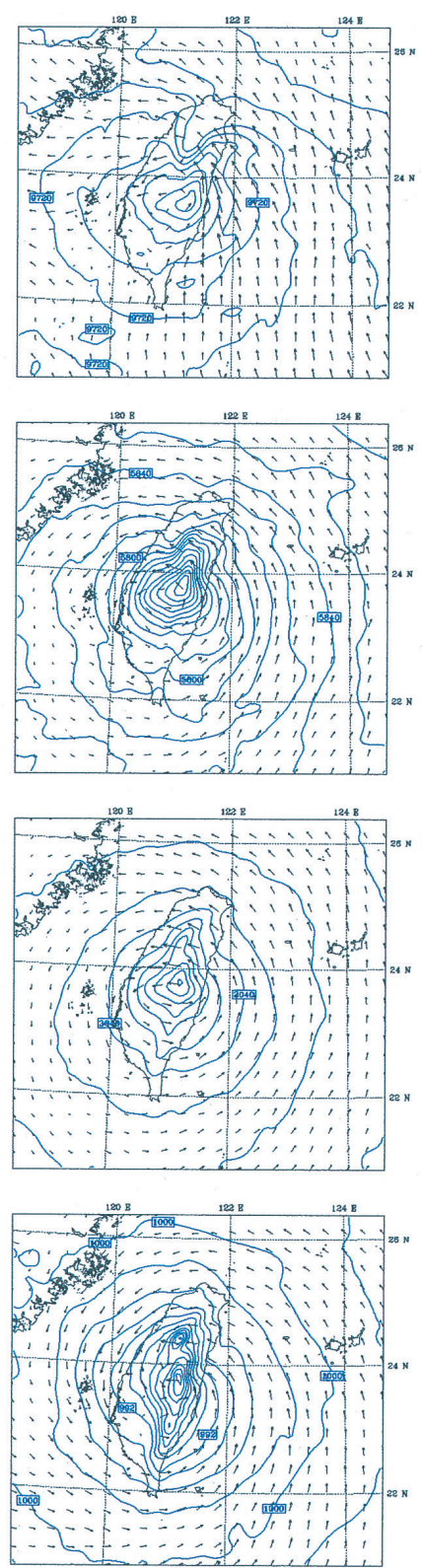

7/30/00UTC
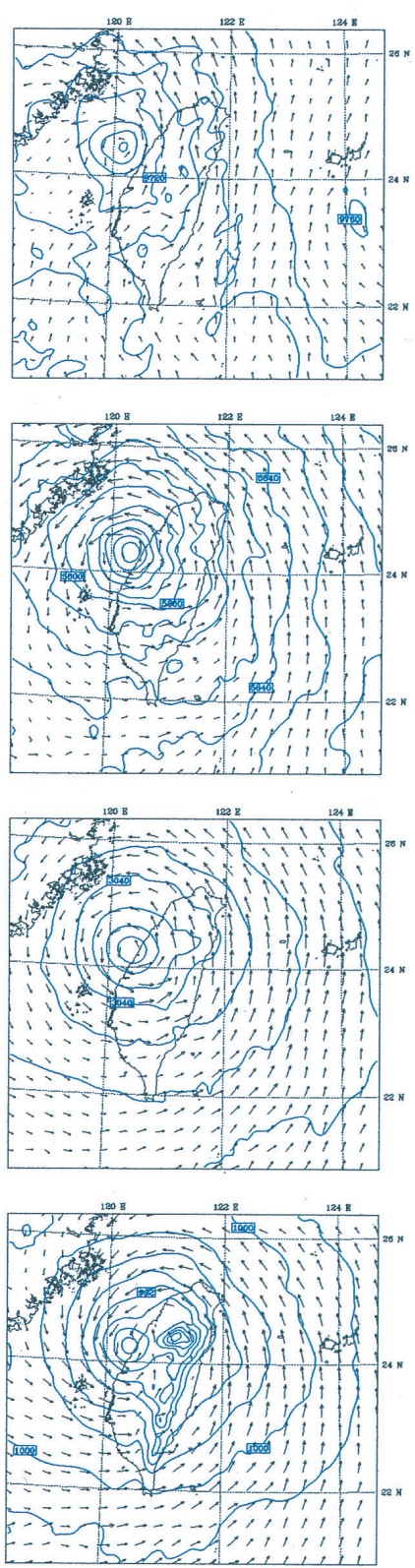

Fig. 17. Horizontal wind vector and geopotential height fields (sea-level pressure for surface level) at 7/29/12UTC, 18UTC, and 7/30/00UTC 2001 for (a) surface, (b) 700, (c) 500, and (c) $300 \mathrm{hPa}$ of the MRF experiment. Contour intervals are $2 \mathrm{hPa}$ on the surface field, $20 \mathrm{~m}$ on the $700-\mathrm{hPa}$ field, and $10 \mathrm{~m}$ on the $500-\mathrm{hPa}$ and $300-\mathrm{hPa}$ fields. 


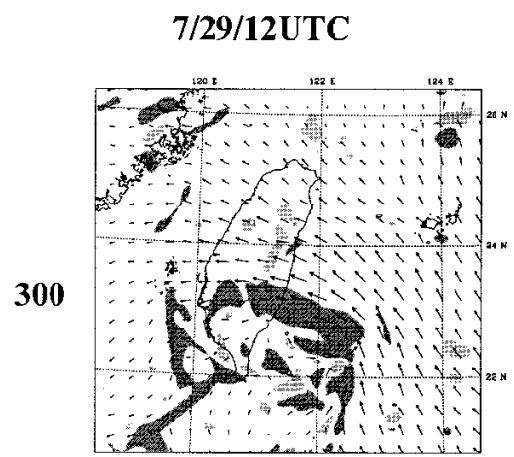

7/29/18UTC
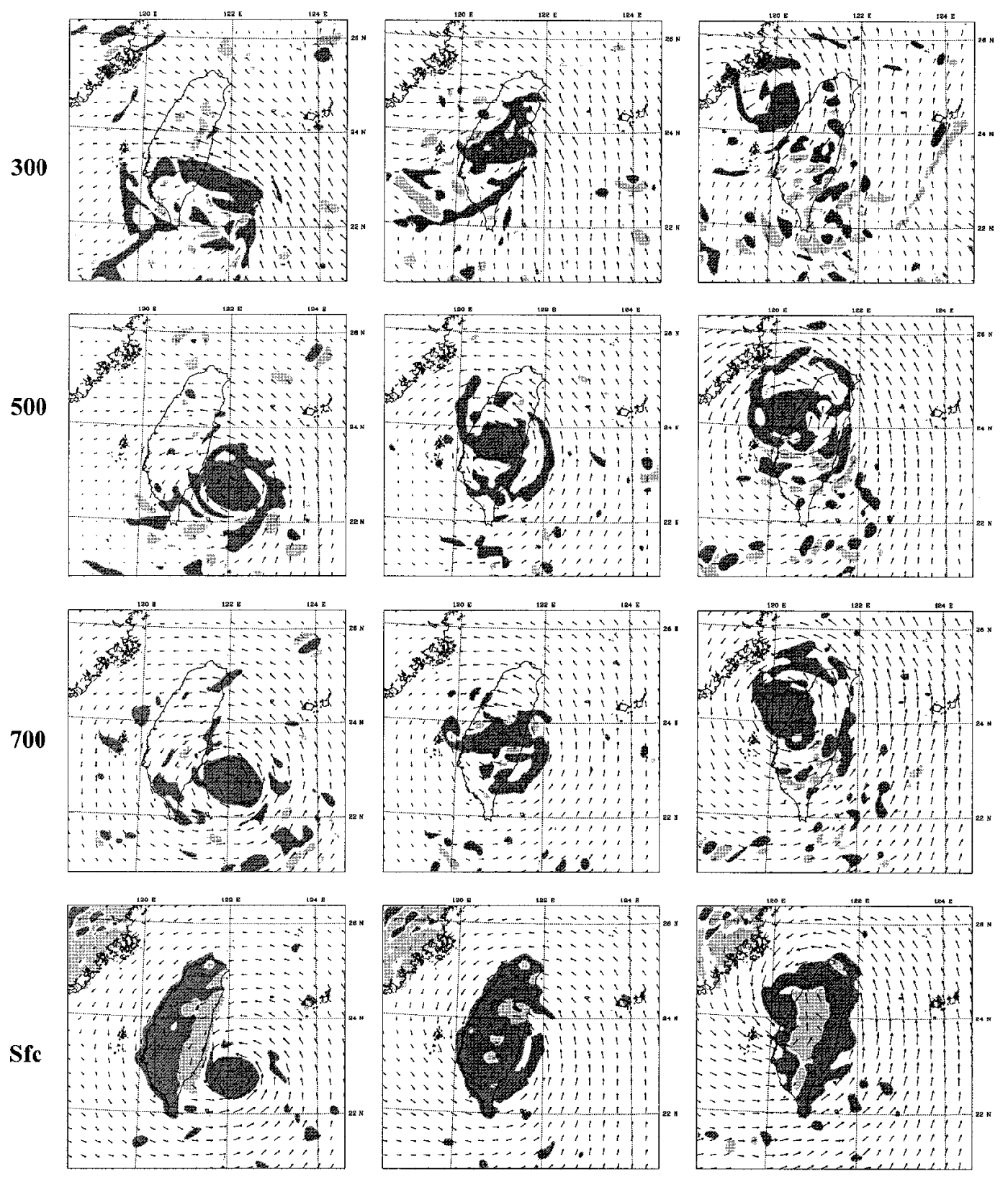

Fig. 18. Same as Fig. 17 except for horizontal wind vector and relative vorticity fields. Positive relative vorticity greater than $20 \times 10^{-5} \mathrm{~s}^{-1}$ is in heavy shading, and negative relative vorticity less than $-20 \times 10^{-5} \mathrm{~s}^{-1}$ is in light shading. 
The uppes-level ( $300 \mathrm{hPa}$ ) center was able to help the surface to 500-hPa cyclone spin up and regain its vertically coherent structure. This downward influence of upper-level potential vorticity (PV) signature can be seen clearly from the NW-SE vertical cross section (across the CMR) at 7/29/20UTC (Fig. 19). The PV field (in units of PVU; $1 \mathrm{PVU}=10^{-6} \mathrm{~m}^{2} \mathrm{~s}^{-1} \mathrm{~K} \mathrm{~kg}^{-1}$ ) is calculated using the hydrostatic approximation form of the Ertel potential vorticity:

$$
P V=-g\left[\frac{\partial \theta}{\partial p}\left(\frac{\partial v}{\partial x}-\frac{\partial u}{\partial y}+f\right)-\frac{\partial v}{\partial p} \frac{\partial \theta}{\partial x}+\frac{\partial u}{\partial p} \frac{\partial \theta}{\partial y}\right]
$$

where $\mathrm{g}$ is the gravitational acceleration, $\theta$ the potential temperature, $u$ the zonal velocity, $v$ the meridional velocity, $f$ the Coriolis parameter, $x$ the east-west distance, $y$ the north-south distance, and $p$ the pressure. Note that the surface secondary low was still located at northwestern Taiwan at this time (Fig. 17), while the surface typhoon center was collated with the upper-level circulation center.

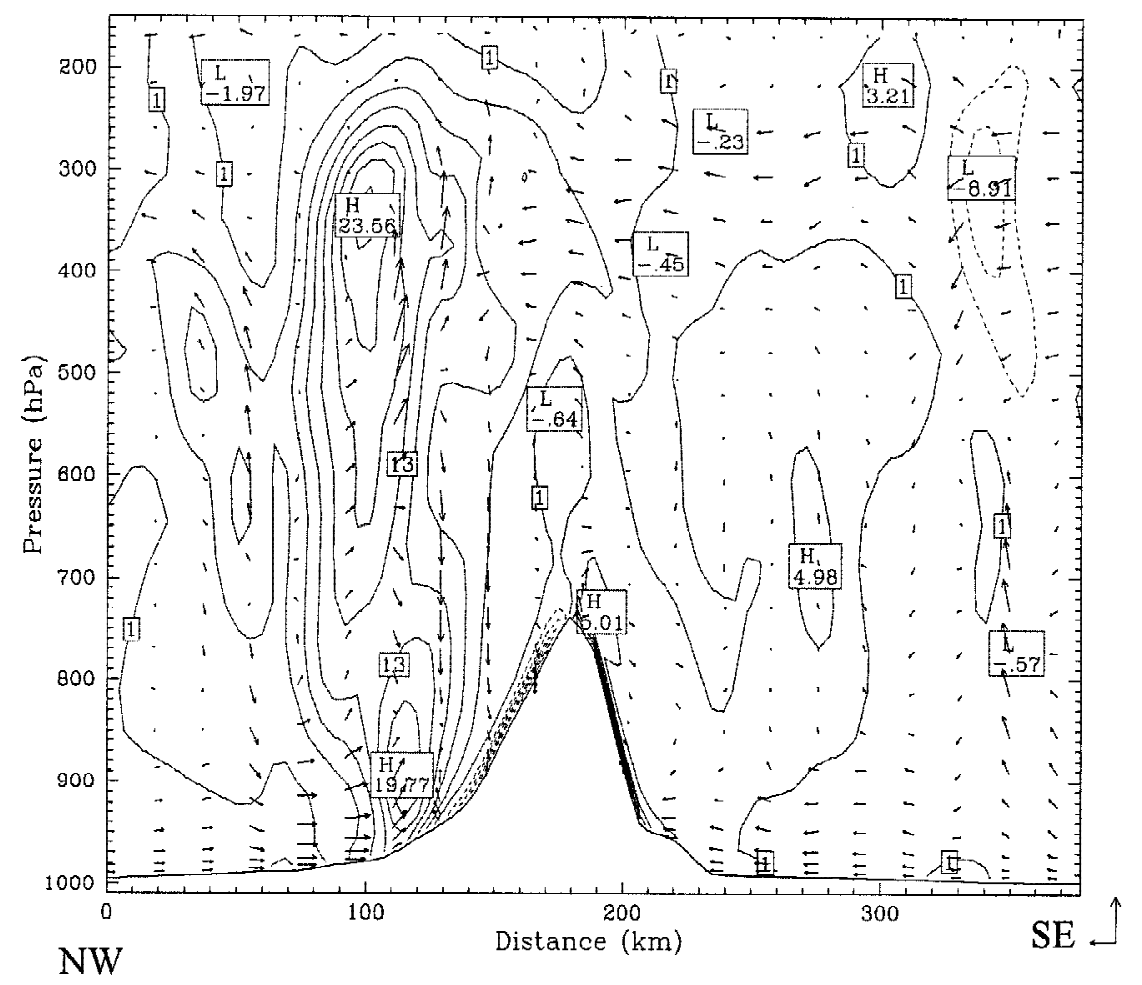

Fig. 19. Vertical cross section of potential vorticity (PV) field at 7/29/20UTC for the best-physics experiment. Contour interval is 1 PVU. Positive PV fields are in solid lines, negative PV dashed lines, and the zero-contour lines are omitted. 


\subsection{Momentum Budget}

In order to better understand the physical mechanisms responsible for the westward turning of Toraji's track before its landfall, a momentum budget is calculated over a square area centered on the simulated Toraji's eye. The $u$ - and $v$-momentum equations in the MM5 (Grell et al. 1994) are:

$$
\frac{\partial u}{\partial t}=-\left[m u \frac{\partial u}{\partial x}+m v \frac{\partial u}{\partial y}+\dot{\sigma} \frac{\partial u}{\partial \sigma}\right]-\frac{m}{\rho}\left[\frac{\partial p^{\prime}}{\partial x}-\frac{\sigma}{P^{*}} \frac{\partial p^{*}}{\partial x} \frac{\partial p^{\prime}}{\partial \sigma}\right]+f v+D_{u}
$$

and

$$
\frac{\partial v}{\partial t}=-\left[m u \frac{\partial v}{\partial x}+m v \frac{\partial v}{\partial y}+\dot{\sigma} \frac{\partial v}{\partial \sigma}\right]-\frac{m}{\rho}\left[\frac{\partial p^{\prime}}{\partial y}-\frac{\sigma}{P^{*}} \frac{\partial p^{*}}{\partial y} \frac{\partial p^{\prime}}{\partial \sigma}\right]-f u+D_{v}
$$

where $p^{*}=p_{s}-p_{t}, p_{s}$ is the surface pressure, $p_{t}$ the model-top pressure, $p^{\prime}$ the perturbation pressure (deviation from the hydrostatic pressure), $\dot{\sigma}$ the vertical velocity, $m$ the mapping factor, $D_{u}$ the turbulent mixing and friction in the $x$ direction, and $D_{v}$ the turbulent mixing and friction in the y direction. Note that the terms associated with the earth curvature are ignored in (1) and (2), since they are trivial in the momentum-budget calculation here. The physical meaning of each term on the right-hand side of Eqs. (1) and (2) is the advection (ADV), pressure-gradient force (PGF), Coriolis force (COR), and turbulent mixing and friction (TUB), respectively; the sum of all these terms is the local tendency (TEN).

The vertical profile of each momentum-budget term horizontally averaged over a square area (19 grid points on each side on the $6.67-\mathrm{km}$ grid or $120 \mathrm{~km}$ in length) and temporally averaged over a one-hour period (1130-1230 UTC 29 July 2001 with a 5-min data interval), when Toraji began to turn westward (see Fig. 1), is shown in Fig. 20. This momentum budget is calculated over a typhoon-following square area (i.e., in a storm-relative coordinate), where Toraji's eye is always located at the center, and the square includes most of the active circulation (inner core and rainbands). It is evident in Fig. 20 that the local momentum tendency mainly results from the difference between two large terms (pressure-gradient force and advection), as indicated in Yang and Houze (1996). In the zonal direction (Fig. 20a), the net positive acceleration (TEN) slows down Toraji's westward propagation, and this positive (eastward) acceleration is mainly produced by the advection process (mostly by horizontal advection) due to flow blocking. In the meridional direction (Fig. 20b), the negative (southward) acceleration in TEN is primarily caused by the advection term.

The net effect of momentum budget on storm motion can be seen in Fig. 21, which shows the time- (1-h) and tropospheric-averaged steering flows at 1130 and 1230 UTC 29 July 2001 over the same square area, as well as their difference vector. The tropospheric-averaged steering flow $\left(\mathbf{V}_{\text {SDLM }}\right)$ is the deep-layer-mean $\left(p_{s}-200 \mathrm{hPa}\right)$ wind vector defined as: 


$$
\mathbf{V}_{\text {SDLM }}=\frac{\int_{p_{s}}^{200} \mathbf{V}_{\mathbf{S}}(p) d p}{\int_{p_{s}}^{200 h P a} d p},
$$

where $\mathbf{V}_{\mathbf{S}}(p)$ is the horizontal wind averaged over the same square area (120 km by $\left.120 \mathrm{~km}\right)$ centered on Toraji's eye at each $p$-level. It is clear from Fig. 21 that there was a westward turning of the tropospheric-averaged steering flows from 1130 UTC to 1230 UTC 29 July 2001 , which resulted from the combination of net positive zonal and negative meridional accelerations by the horizontal advection process (see TEN in Fig. 20), as shown clearly in the difference vector.

\subsection{Control Parameter Analysis}

Table 3 lists the values for the control parameters of $V_{\max }, R, V_{\max } / N h, V_{\max } / U, V_{\max } / R f$, and $R / L_{y}$ for Typhoon Toraji (2001). The parameter $V_{\max }$ is the TC's maximum tangential wind, $N$ the Brunt-Väisälä frequency, $h$ the mountain height, $U$ the basic flow speed perpendicular to the mountain, $R$ the TC's radius of maximum wind, and $L_{y}$ the north-south scale of the mountain. Lin et al. (2002) indicated that when $V_{\max } / N h, V_{\max } / U$, and $V_{\max } / R f$ are simultaneously large, such as $V_{\max } / N h>1.6, V_{\max } / U>7.0$, and $V_{\max } / R f>4.0$, then the TC track is continuous. Otherwise, the TC track is discontinuous. Lin et al. (2005) further showed that when the nondimensional parameter of $R / L_{y}$ is small (large), the TC's track would be discontinuous (continuous), and the track deflection is large (small). The nondimensional control parameter $V_{\max } / N h$ may be regarded as a vortex Froude number of the airstream associated with a typhoon's tangential circulation. The control parameter $V_{\max } / U$ measures the relative strength of the typhoon vortex compared to the basic flow. In other words, $V_{\max } / U$ may be viewed as the ratio of the vortex Froude number to the basic-state Froude number, $\left(V_{\max } / N h\right) /$ $(U / N h)$. The nondimensional parameter $V_{\max } / R f$ is a measure of the ratio of vortex vorticity $\left(V_{\max } / R\right)$ to planetary vorticity $(f)$. Thus, the parameters $V_{\max } / U$ and $V_{\max } / R f$ are both related to the ratio of the strength of a vortex to the basic-state flow and then are not totally independent to each other. See Lin et al. $(2002 ; 2005)$ for detailed discussion of the physical meanings of these nondimensional parameters.

Table 3 shows that for all numerical experiments, parameters $V_{\max } / N h$ are all less than 1.6 (resulting in a discontinuous track), only one parameter of $V_{\max } / U$ is greater than 7.0 (for a discontinuous track), all parameters of $V_{\max } / R f$ are greater than 4.0 (for a continuous track), and all parameters of $R / L_{y}$ are less than 0.35 (for a large track deflection). Three control parameters indicate a discontinuous track, and only one control parameter implies a continuous track, thus resulting in discontinuous tracks for most TCs, which are consistent with most westward (anticyclonically) turning tracks in Fig. 5. However, there are still some storms displaying cyclonically turning tracks (like the BT and PX experiments), and this might be due to nonlinear or small-scale moisture effects which are not considered in the linear dynamics argument of control parameters analysis proposed by Lin et al. (2002; 2005). 

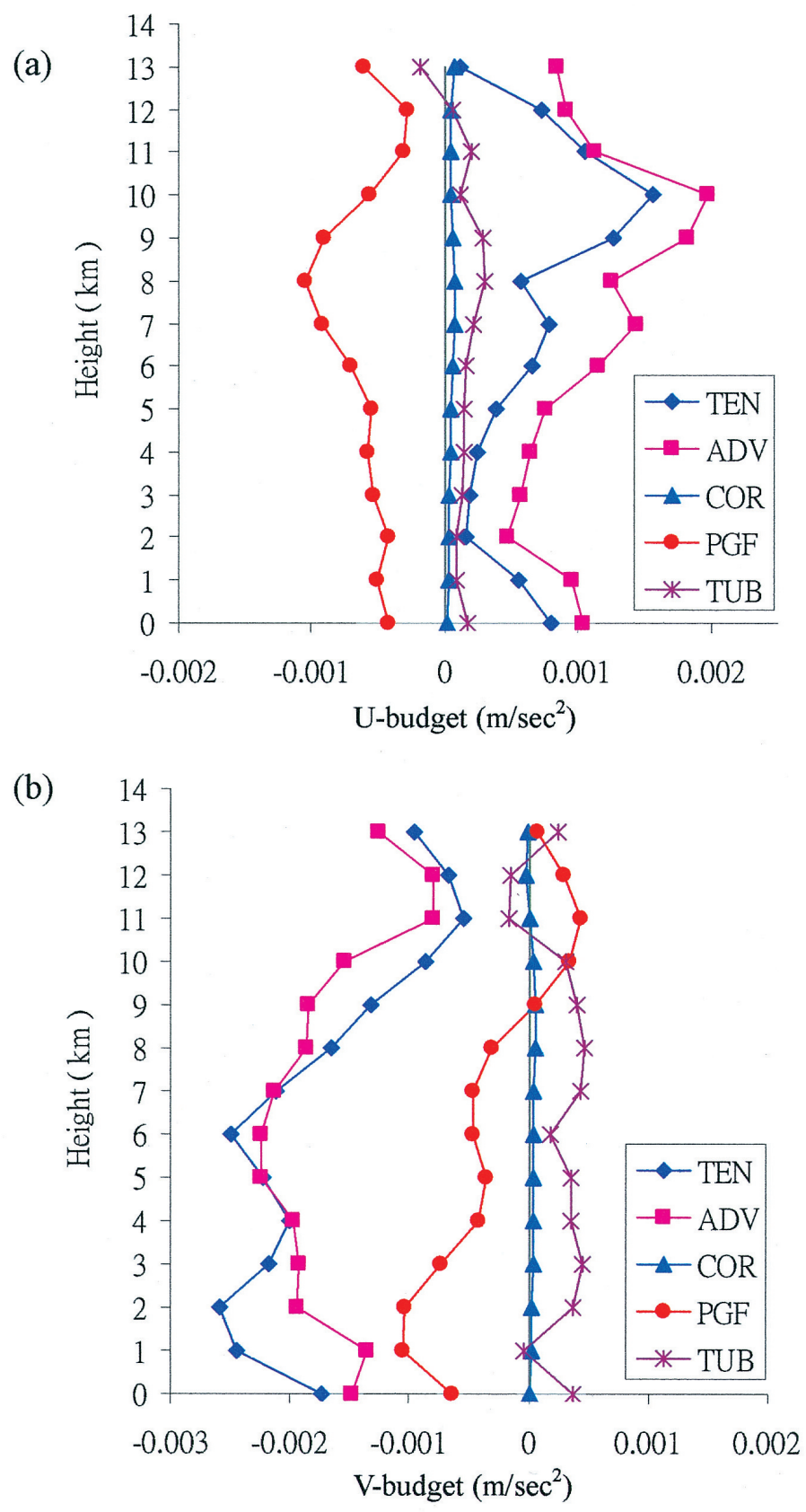

Fig. 20. Vertical profile of (a) $u$-momentum and (b) $v$-momentum budget terms averaged over a square area around Toraji's center and over a 1-h period (1130-1230 UTC 29 July 2001). See text for the definition of each budget term. 


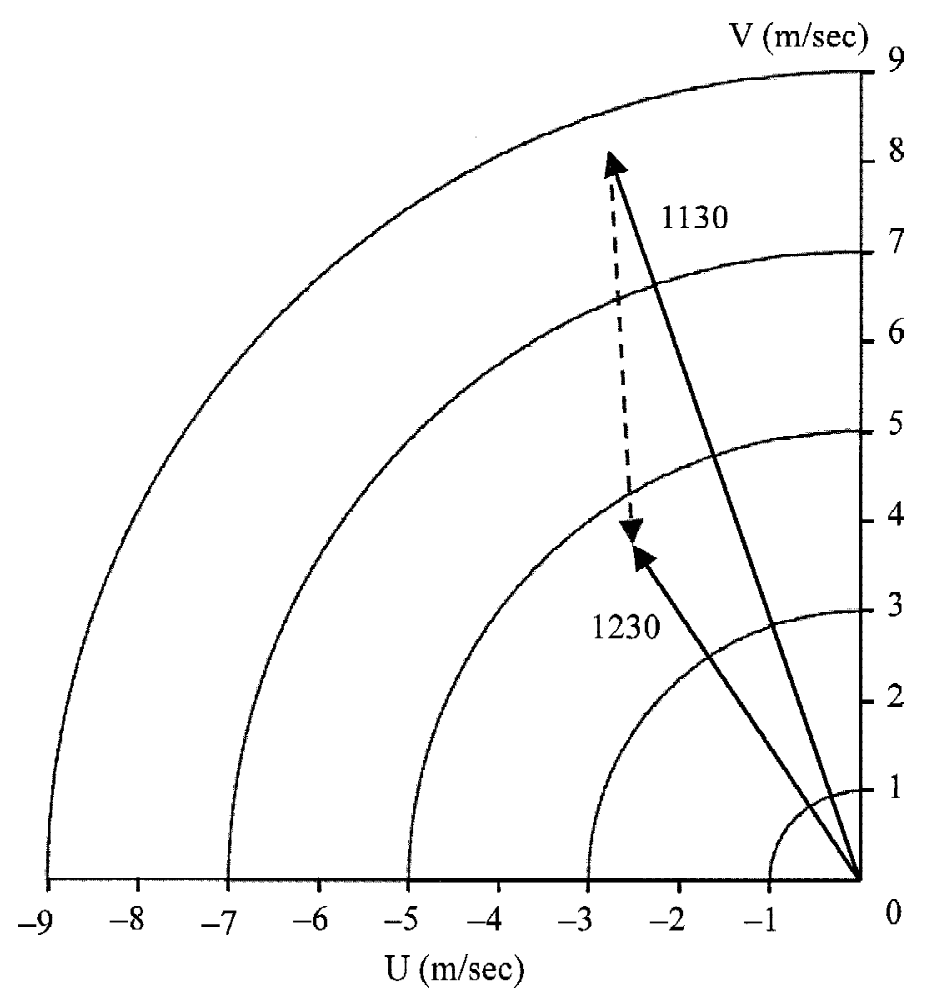

Fig. 21. Solid arrows are velocity vectors of the time- (1-h) and troposphericaveraged steering flows around Typhoon Toraji at 1130 and 1230 UTC 29 July 2001, and dashed arrow is the difference vector.

\section{CONCLUSIONS}

Typhoon Toraji (2001) followed a very straight (southeast to northwest) track as it approached Taiwan, and made landfall over Hualian County at 1610 UTC 29 July 2001, and hit directly into the Central Mountain Range (CMR). After crossing the CMR in 10 hours, it produced copious rainfall, severe debris flows and mudslides, and caused more than 100 deaths and about 300 people missing or injured. Just before landfall, Toraji turned west and followed a slightly anticyclonic track across the island, different from the cyclonic track as expected from many previous observational and idealized modeling studies of TCs passing over Taiwan.

In this study, we examine the sensitivity of simulated track, central pressure, wind maximum, and accumulated rainfall of Typhoon Toraji (2001) to physical parameterizations, using a triply-nested Penn State/NCAR MM5 with grid sizes of 60, 20, and $6.67 \mathrm{~km}$, respectively. Three sets of five numerical experiments on cumulus, cloud microphysics, and PBL parameterizations are performed (15 experiments totally). Among subgrid-scale cumulus schemes tested, the simulated typhoon with the Grell scheme has the best track. For grid-scale cloud microphysics scheme examined, all storms have similar tracks, with the best simulated 
Table 3. Parameters of flow regimes of numerical experiments for Typhoon Toraji (2001) passing through Taiwan's CMR. The common factors for each experiment are $\mathrm{U}=5.9 \mathrm{~m} \mathrm{~s}^{-1}, \mathrm{~N}=0.01 \mathrm{~s}^{-1}, \mathrm{~h}=3000 \mathrm{~m}, \mathrm{Ly}=$ $230 \mathrm{~km}, \mathrm{f}=5.8^{\circ}-10-5 \mathrm{~s}^{-1}$, and $\mathrm{U} / \mathrm{Nh}=0.197$.

\begin{tabular}{ccccccc}
\hline Member & $\begin{array}{c}V_{\max } \\
\left(\mathrm{m} \mathrm{s}^{-1}\right)\end{array}$ & $\begin{array}{c}R \\
(\mathrm{~km})\end{array}$ & $\frac{V_{\max }}{N h}$ & $\frac{V_{\max }}{U}$ & $\frac{V_{\max }}{R f}$ & $\frac{R}{L_{y}}$ \\
\hline AK & 32.60 & 61.26 & 1.087 & 5.53 & 9.18 & 0.27 \\
GR & 37.39 & 52.09 & 1.246 & 6.34 & 12.37 & 0.23 \\
KF & 34.75 & 45.79 & 1.158 & 5.89 & 13.08 & 0.20 \\
BM & 33.18 & 42.30 & 1.106 & 5.62 & 13.52 & 0.18 \\
KF2 & 31.98 & 43.64 & 1.066 & 5.42 & 12.63 & 0.19 \\
\hline WR & 39.96 & 40.57 & 1.332 & 6.77 & 16.98 & 0.18 \\
ICE & 38.18 & 37.73 & 1.273 & 6.47 & 17.45 & 0.16 \\
MP & 44.00 & 38.89 & 1.467 & 7.46 & 19.51 & 0.17 \\
GG & 37.39 & 52.09 & 1.246 & 6.34 & 12.37 & 0.23 \\
SCH & 40.35 & 42.18 & 1.345 & 6.84 & 16.49 & 0.18 \\
\hline BD & 32.56 & 44.74 & 1.085 & 5.52 & 12.55 & 0.19 \\
BT & 35.22 & 53.36 & 1.174 & 5.97 & 11.38 & 0.23 \\
ETA & 34.93 & 35.92 & 1.164 & 5.92 & 16.77 & 0.16 \\
MRF & 37.39 & 52.09 & 1.246 & 6.34 & 12.37 & 0.23 \\
PX & 34.00 & 74.57 & 1.133 & 5.76 & 7.86 & 0.32 \\
\hline \hline
\end{tabular}

track using the Goddard Graupel cloud microphysics scheme and the lowest central pressure using the Warm Rain scheme. The reason is that all hydrometeors in the Warm Rain experiment are heavy raindrops (compared to additional light ice particles and snowflakes in other microphysics experiments), falling out quickly and concentrating around the eyewall region, thus hydrostatically producing the lowest central pressure as shown in Wang (2002). The PBL parameterization significantly influences the simulated typhoon tracks, and the Medium-Range Forecast model PBL generated storm with the track and intensity which most resemble actual observations.

An experiment with the best scheme from each of three sets of physical parameterization experiments has the best performance in terms of central pressure, wind maximum and accumulated rainfall, and it can simulate the westward turning of Toraji's track before the landfall. Standard deviation and ensemble (arithmetic) mean are calculated for each set of physical 
parameterization experiments. The observed track is within the one-standard-deviation track envelop, and the ensemble-mean rainfall distribution is much closer to the observed than each individual experiment.

A combination of the topographically- and synoptically-induced vertical moisture fluxes, calculated based on the flux model of Lin et al. (2001), corresponds quite well to the hourly surface rainfall distribution. Six hours before landfall, Toraji's pressure center was vertically coherent with its circulation center. A secondary low was located over the northwestern coastal plain, which was produced by vorticity stretching and the adiabatic warming associated with the strong downslope wind as part of the Toraji's circulation over the northern portion of the CMR. At the time of landfall, pressure ridging occurred over the eastern coast, as a result of flow blocking of Toraji's outer circulation. At the surface, a secondary low over the northwestern coastal plain was roughly as strong as or slightly weaker than Toraji's center over eastern Taiwan; thus Toraji's track was discontinuous as a result of the coexistence of the Toraji and secondary (leeside) centers. Ten hours after landfall, Toraji was leaving Taiwan and entering the Taiwan Strait; the upper-level (300 hPa) center was then able to help the surface to 500-hPa cyclone spin up and regain its vertically coherent structure.

Analysis of control parameters for typhoon's track continuity over Taiwan shows that Toraji's westward track discontinuity is consistent with the control parameter analysis discussed in Lin et al. (2002). A momentum budget analysis shows that Toraji's westward turning before landfall mainly results from the horizontal advection process by flow blocking. However, there are still some experiments displaying cyclonically turning tracks, opposite to the observed tracks and most simulated tracks. This might be due to nonlinear or small-scale moisture effects which are not considered in the linear argument of control parameters analysis proposed by Lin et al. (2002; 2005).

Acknowledgements The authors thank reviewers for their constructive comments and suggestions, Prof. Ching-Hwang Liu for his suggestion of the best physics experiment, and Prof. Yuh-Lang Lin for sharing us his unpublished manuscripts. Use of the MM5 was made possible by the Mesoscale and Microscale Meteorological Division of the National Center for Atmospheric Research. Parts of the results are from the second author's M.S. thesis study. This research was supported by the National Science Council in Taiwan under Grants NSC 93-2119-M-008-010-AP1 and NSC 93-2625-Z-008-012 (IHS Publication Series No. 20).

\section{REFERENCES}

Anthes, R. A., 1977: A cumulus parameterization scheme utilizing a one-dimensional cloud model. Mon. Wea. Rev., 105, 270-286.

Bender, M. A., R. E. Tuleya, and Y. Kurihara, 1987: A numerical study of the effect of island terrain on tropical cyclones. Mon. Wea. Rev., 115, 130-155.

Betts A. K., and M. J. Miller, 1986: A new convective adjustment scheme. Part II: Single column tests using GATE wave, BOMEX, ATEX, and Arctic air-mass data sets. Quart. J. Roy. Meteor. Soc., 112, 693-709. 
Blackadar, A. K., 1979: High resolution models of the planetary boundary layer. Advances in Environmental Sciences and Engineering, J. Pfafflin and E. Ziegler, (Eds.), Vol. 1, No. 1, Gordon and Breach, 50-85.

Braun, S. A., and W. K. Tao, 2000: Sensitivity of high-resolution simulations of Hurricane Bob (1991) to planetary boundary layer parameterizations. Mon. Wea. Rev., 128, 39413961.

Burk, S. D., and W. T. Thompson, 1989: A vertically nested regional numerical weather prediction model with second-order closure physics. Mon. Wea. Rev., 117, 2305-2324.

Chang, S. W., 1982: The orographic effects induced by an island mountain range on propagating tropical cyclones. Mon. Wea. Rev., 110, 1255-1270.

Charney, J. G., and A. Eliassen, 1964: On the growth of the hurricane depression.J. Atmos. Sci., 21, 68-75.

Dudhia, J., 1989: Numerical study of convection observed during the Winter Monsoon Experiment using a mesoscale two-dimensional model. J. Atmos. Sci., 46, 3077-3107.

Frank, W. M., 1983: The cumulus parameterization problem. Mon. Wea. Rev., 111, 18591871.

Grell, G. A., 1993: Prognostic evaluation of assumptions used by cumulus parameterizations. Mon. Wea.Rev., 121, 764-787.

Grell, G. A., J. Dudhia, and D. R. Stauffer, 1994: A description of the fifth-generation Penn State/NCAR mesoscale model (MM5). NCAR Technical Note, NCAR/TN-398+STR, $117 \mathrm{pp}$.

Hong, S. Y, and H. L. Pan, 1996: Nonlocal boundary layer vertical diffusion in a mediumrange forecast model. Mon. Wea. Rev., 124, 2322-2339.

Kain, J. S., and J. M. Fritsch, 1993: Convective parameterization for mesoscale models: The Kain-Fritsch scheme. The Representation of Cumulus Convection in Numerical Models, Meteor. Monogr., No. 46, Am. Meteor. Soc., 165-170.

Kain, J. S., 2004: The Kain-Fritsch convective parameterization: an update.J. Appl. Meteor., 43, 170-181.

Kessler, E., 1969: On the distribution and continuity of water substance in atmospheric circulations. Metoro. Monogr., 10, No. 32, Am. Meteor. Soc., 84 pp.

Kuo, H. L., 1965: On formation and intensification of tropical cyclones through latent heat release by cumulus convection. J. Atmos. Sci., 22, 40-63.

Kuo, H. L., 1974: Further studies of the parameterization of the influence of cumulus convection on large-scale flow. J. Atmos. Sci., 31, 1232-1240.

Lin, Y. L., 1993: Orographic effects on airflow and mesoscale weather systems over Taiwan. Terr. Atmos. Ocean. Sci., 4, 381-420.

Lin, Y. L., J. Han, D. W. Hamilton, and C.-Y. Huang, 1999: Orographic influence on a drifting cyclone. J. Atmos. Sci., 56, 534-562.

Lin, Y. L., S. Chiao, T. A. Wang, M. L. Kaplan, and R. P. Weglarz, 2001: Some common ingredients of heavy orographic rainfall. Wea. Forecasting, 16, 633-660.

Lin, Y. L., D. B. Ensley, S. Chiao, and C. Y. Huang, 2002: Orographic influences on rainfall and track deflection associated with the passage of a tropical cyclone.Mon. Wea.Rev., 130, 2929-2950. 
Lin, Y. L., S. Y. Chen, C. M. Hill, and C.-Y. Huang, 2005: Control parameters for the influence of a mesoscale mountain range on cyclone track continuity and deflection.J. Atmos. Sci., in press.

Liu, Y., D. L. Zhang, and M. K. Yau, 1997: A multiscale numerical study of Hurricane Andrew (1992). Part I: Explicit simulation and verification. Mon. Wea. Rev., 125, 30733093.

Low-Nam, S., and C. Davis, 2001: Development of a tropical cyclone bogussing scheme for the MM5 system. Preprint, The 11th PSU-NCAR MM5 Users' Workshop, 130-134.

Mellor, G. L., and T. Yamada, 1982: Development of a turbulence closure model for geophysical fluid problems. Rev. Geophys. Space Phys., 20, 851-875.

Ooyama, K., 1969: Numerical simulation of the life cycle of tropical cyclones.J. Atmos. Sci., 26, 3-40.

Ooyama, K., 1982: Conceptual evolution of the theory and modeling of the tropical cyclone. J. Meteor. Soc. Japan, 60, 369-379.

Reisner, J., R. T. Bruintjes, and R. J. Rasmussen, 1998: Explicit forecasting of supercooled water in winter storms using the MM5 mesoscale model. Quart. J. Roy. Meteor. Soc., 124B, 1071-1107.

Schultz, P., 1995: An explicit cloud physics parameterization for operational numerical weather prediction. Mon. Wea. Rev., 123, 3331-3343.

Smith, R. B., 1979: The influence of mountains on the atmosphere. Advances in Geophysics, Vol. 21, Academic Press, 87-230.

Tao, W. K., and J. Simpson, 1993: The Goddard cumulus ensemble model. Part I: Model description. Terr., Atmos., Ocean. Sci., 4, 35-72.

Wang, S. T., 1980: Prediction of the movement and strength of typhoons in Taiwan and its vicinity (in Chinese). Nat. Sci. Coun. Res. Rept. 108, Taipei, Tawan, 100 pp.

Wang, Y., 2002: An explicit simulation of tropical cyclones with a triply nested movable mesh primitive equation model: TCM3. Part II: Model refinements and sensitivity to cloud microphysics parameterization. Mon. Wea. Rev., 130, 3022-3036.

Warner, T. T., and H. M. Hsu, 2000: Nested-model simulation of moist convection: The impact of coarse-grid parameterized convection on fine-grid resolved convection.Mon. Wea. Rev., 128, 2211-2231.

Wu, C. C., and Y. H. Kuo, 1999: Typhoons affecting Taiwan: Current understanding and future challenges. Bull. Am. Meteor. Soc., 80, 67-80.

Wu, C. C., T. H. Yen, Y. H. Kuo, and W. Wang, 2002: Rainfall simulation associated with Typhoon Herb (1996) near Taiwan. Part I: The topographic effect. Wea. Forecasting, 17, 1001-1015.

Xiu, A., and J. E. Pleim, 2000: Development of a land surface model. Part I: Application in a mesoscale meteorology model. J. Appl. Meteor., 40, 192-209.

Yang, M. J., and R. A. Houze, Jr. 1995: Sensitivity of squall-line rear inflow to ice microphysics and environmental humidity. Mon. Wea. Rev., 123, 3175-3193.

Yang, M. J., and R. A. Houze, Jr., 1996: Momentum budget of a squall line with trailing stratiform precipitation: Calculations with a high-resolution numerical model.J. Atmos. Sci., 53, 3629-3652. 
Yang, M. J., Ben J. D. Jou, S. C. Wang, J. S. Hong, P. L. Lin, J. H. Teng, and H. C. Lin, 2004: Ensemble prediction of rainfall during the 2000-2002 Mei-Yu seasons: Evaluation over the Taiwan area. J. Geophys. Res., 109, D18203. doi:10.1029/2003JD004368.

Yeh, T. C., and R. L. Elsberry, 1993a: Interaction of typhoons with the Taiwan orography. Part I: Upstream track deflections. Mon. Wea. Rev., 121, 3193-3212.

Yeh, T. C., and R. L. Elsberry, 1993b: Interaction of typhoons with the Taiwan orography. Part II: Continuous and discontinuous tracks across the island. Mon. Wea. Rev., 121, 3213-3233. 